\title{
RELATIONSHIPS, COMPETITION, AND THE STRUCTURE OF INVESTMENT BANKING MARKETS
}

\author{
BHARAT N. ANAND \\ ALEXANDER GALETOVIC
}

\section{SERIE ECONOMIA N96}

\author{
Diciembre, 2000
}

\author{
Centro de Economía Aplicada \\ Departamento de Ingeniería Industrial \\ Facultad de Ciencias Físicas y Matemáticas \\ Universidad de Chile
}




\title{
Relationships, Competition, and the Structure of Investment Banking Markets*
}

\author{
Bharat N. Anand ${ }^{\dagger}$ \\ Harvard Business School
}

\author{
Alexander Galetovic ${ }^{\ddagger}$ \\ Universidad de Chile
}

December 2000

\begin{abstract}
Previous studies have acknowledged the tradeoff between relationships and competition in financial intermediation. In this paper, we explore the structural determinants of this tradeoff in the investment banking market, by deriving it from the underlying relationship technology. In the model, each of several banks incurs a sunk cost to establish a relationship with the same firm; all compete for doing its deals. Alternatively, the firm can do deals with other banks on an arm's-length basis.

We study the role of a self-enforcing norm that restrains price undercutting on the incentives to make relationship-specific investments. We find that banks establish relationships even without local or aggregate monopoly power. Moreover, relationship banks make profits despite a competitive fringe of arm's-length banks. Finally, a dual market structure emerges in equilibrium - a small number of relationship banks serve firms that make large and frequent deals; a competitive arm's-length segment serves firms that make small and infrequent deals; and, competitive conditions in the fringe segment do not affect the relationship segment. In this way, we reconcile the coexistence of competitive and seemingly collusive features of this industry, which have been noted by many observers.

We apply our framework to provide a logic for antitrust analysis of the industry, to examine the consequences of global competition and discuss the effect of the Internet on bank-firm relationships.
\end{abstract}

Key words: investment banking, loose linkage, relationships, sunk costs. JEL classification: G20, L22

\footnotetext{
* We thank Bill Wilhelm, Felipe Zurita and seminar participants at the Central Bank of Chile for comments.

$\dagger$ Soldiers Field Road, Boston, MA 02163. Phone: (617) 495-5082; Fax: (617) 495-0355; email: banand@hbs.edu. Anand gratefully acknowledges the financial support of the Division of Research at Harvard Business School.

$\ddagger$ Centro de Economia Aplicada (CEA), Av. Republica 701, Santiago, Chile. Phone: +56/2-678-4065; Fax: +56/2-689-7895; email: agaleto@dii.uchile.cl. Galetovic gratefully acknowledges the financial support of Fondecyt, Fundación Andes, the Hewlett Foundation and the Mellon Foundation.
} 


\section{Introduction}

The tension between relationships and competition in banking is well established in the literature. ${ }^{1}$ By now, it is well known that banks should be willing to incur the sunk costs of establishing relationships only if imperfect competition creates rents that compensate these costs. In most analyses, however, imperfect competition and rents are taken as exogenous. In this paper we explore the structural determinants of the relationship-competition tradeoff in the investment banking market and examine the determinants of market structure. We show that understanding where market structure comes from is important to analyzing many issues of pressing concern, such as the recent trend towards more competition, which many think to be deleterious for relationships. ${ }^{2}$

Investment banking is a natural market to study these issues. Relationships between banks and security issuers have always been important. ${ }^{3}$ Moreover, while this market is very competitive in many dimensions and bulge-bracket banks coexist with a large fringe of smaller ones, they have somehow avoided cutthroat price competition. Since soft price competition is necessary to preserving the incentives to establish relationships, understanding how competition and cooperation are reconciled in this market should lead to useful insights on the relationships-competition tradeoff. Last, unlike other intermediaries such as commercial banks, the structure of investment banking has been largely unregulated. Consequently, the observed concentrated structure, which should soften price competition, is likely to be an endogenous adaptation to support relationships which is not "contaminated" by regulation.

Focusing on the structural determinants of the tradeoff between relationships and competition leads to a richer characterization of the conditions necessary to preserve incentives to make relationship-specific investments. Neither aggregate nor local monopoly power are necessary. Moreover, competition from a fringe need not kill relationships. The only requirement to sustain relationships is a self-enforcing norm that restrains price undercutting. This norm follows directly from the underlying relationship technology, and does restrict the feasible market structures. It also shows that assuming an exogenous market structure ignores one important margin of adjustment - many changes that seem to weaken relationships may instead induce endogenous adjustments in market structure that undo their deleterious effects. For example, when firms increase the number of banks with whom they have relationships (thus increasing the intensity of competition), this may lead to a more concentrated banking market.

The rest of the paper proceeds as follows. In section 2 , we describe the some facts of the investment banking market, present an intuitive discussion of the main results, and relate the paper

\footnotetext{
${ }^{1}$ For the general theory see Harris and Holmstrom (1982). For analysis of the problem in financial markets, see, for example, Allen and Gale (2000, ch.10.6), Aoki and Dinc (1997), Hellwig (1991), Mayer (1988), Rajan (1992, 1995).

${ }^{2}$ For example, Boot and Thakor (2000) entitled their recent paper "Can Relationships Survive Competition?".

${ }^{3}$ See, for example, Baker (1990), Eccles and Crane (1988), and Hayes and Regan (1994).
} 
with the literature. Section 3 formally describes the model. In section 4 we solve the model and present the main results. Section 5 extends the model to consider nonprice competition. Section 6 applies the model to provide a logic for antitrust analysis, examines the consequences of global competition and discusses the effect of the Internet on bank-firm relationships. Section 7 concludes.

\section{Facts, model sketch, and relation with the literature}

\subsection{Some facts of the investment banking market}

By now there is a large body of evidence on the institutional features, practices and structure of the investment banking market. ${ }^{4,5}$ What pervades the facts, however, is a coexistence of competitive and apparently collusive features. As Rajan (1995) points out, “... it is unlikely that the securities business is the textbook competitive industry." 6

The first fact is the existence of relationships between large firms and investment banks. Baker (1990) examined ties between investment banks and corporations with market values of $\$ 50$ million or more between 1981 and 1985. He reports that for the 1091 corporations that made two or more deals during this period, the average number of lead banks used per firm is three (these firms made eight deals on average). All but nine granted more than $50 \%$ of their business to their top three banks and, on average, $59 \%$ of the business was allocated to the top bank. Eccles and Crane (1988, ch.4) similarly report that among the 500 most active corporations in the market during 1984-1986, 55.6\% used predominantly one bank to float their securities, with the rest maintaining relationships with only a few banks. James (1992) finds that in the first common stock security offering after an IPO, $72 \%$ of firms choose the same lead bank as before; for debt offerings, $65 \%$ of issuers do not switch banks.

The second fact is soft price competition. For example, Matthews (1994 p. 161) notes that spreads on high-quality, long-term corporate bonds have been $7 / 8 \%$ of capital raised for many decades. Similarly, in England, underwriting fees have been $1.25 \%$ of the capital raised, for several decades as well. ${ }^{7}$ And recently, Chen and Ritter (2000) document the remarkable clustering of IPO

\footnotetext{
${ }^{4}$ Activities of investment banks can be classified into three broad categories, investment banking, trading \& principal investments, and asset management \& security services (see Wilhelm and Downing [forthcoming, ch. 3]). In this paper our focus is on investment banking activities, which comprise equity and debt underwriting, financial restructuring and $\mathrm{M} \& \mathrm{~A}$ advisory services.

${ }^{5}$ For summaries of these facts see Auerbach and Hayes (1986), Bloch (1989), Carosso (1970), Eccles and Crane (1988), Hayes et al (1983), Hayes and Hubbard (1990), Matthews (1994), Wilhelm and Downing (forthcoming) and Anand and Galetovic (2000).

${ }^{6}$ Rajan also points out that "If indeed there are excess profits (and I am not arguing that there are), economists must understand the source of these profits. [...] Without understanding the nature of the securities business in a particular economy, vacuous statements such as 'allowing more entry implies more competition' are unhelpful at best, and dangerous at worst."

${ }^{7}$ See "Some Old Peculiar Practices in the City of London," The Economist (February 18, 1995).
} 
spreads at seven percent. ${ }^{8}$ Explanations have focused either on explicit or implicit collusion, ${ }^{9}$ or on average cost pricing behavior.

The third fact is high concentration, this regardless of the time period and investmentbanking category. For example, the top six investment banks accounted for $76 \%$ of the securities underwriting volume in 1986, for $72 \%$ of total M\&A deal volume on which they were advisors between 1983 and 1997, and 91\% of Rule 415 debt underwritings in 1988. ${ }^{10}$ Explanations have focused on scale economies, product differentiation, and reputational barriers to entry. However, while each implies that concentration must fall as the market grows, in practice market structure has been remarkably stable over time. For example, this is apparent in Figures 1 and 2, which plot top- 8 concentration ratios and market volume in underwriting and M\&A, respectively, over long time periods. High concentration also seems to be accompanied by excess returns. Matthews (1994, p.228) reports that the pre-tax return on equity for large investment banks was on average close to $30 \%$ between 1981 and 1991 .

At the same time, there are signs that investment banking is very competitive. To begin, the importance of relationships varies both cross-sectionally and over time. Many small firms seem to engage banks on an as-needed basis and there is consistently a large fringe of smaller investment banks available in the market. Moreover, firms are more likely now to establish relationships with multiple investment banks, which, in turn, actively solicit business and intensely compete in nonprice dimensions (e.g., sales effort, advertising).

Switching costs beween investment banks do not seem significant either. As Eccles and Crane (1988) point out, a key feature of relationships is the "loose linkage" that exists between the costs that investment banks incur in establishing and maintaining relationships, and the fees they generate from deals. Indeed, there are no fixed-fee contracts, and fees are set at the time of each deal, when the costs incurred to establish and maintain relationships are already sunk. Second, most large banks appear to reside within the same "strategic group". Hayes et al. (1983) find that investment banks can be grouped into four major clusters according to the types of firms they make deals with, but each cluster contains at least two of the major banks. Further, all major investment banks are multiproduct firms. And, as Eccles and Crane (1988, p. 104) note, while some banks specialize somewhat according to industry, major investment banks have an important presence in

\footnotetext{
${ }^{8}$ See also "Overcharging Underwriters" (The Economist, June 27, 1998), where it is noted that "... studies in both countries suggest issuing companies are overcharged, and that they are stung for more in America." Similar attributions to bankers can be found elsewhere, as noted by Chen and Ritter (2000, p. 1106).

${ }^{9}$ See, for example, the account of the antitrust case against investment banks in the late 1940s in Carosso (1970).

${ }^{10}$ The sources are, respectively, Eccles and Crane (1988), SDC data on M\&A deals processed by the authors, and Hayes and Regan (1993). The high market concentration in the industry is also noted in various articles in The Economist. See, for example, "Investment Banking Boutiques: Small Fried" (June 8, 1996); "Fools' Gold" (December 13, 1997); "Pretenders to the Crown" (April 17, 1999).
} 
all. ${ }^{11}$ Third, intellectual property rights over product innovations are weak (Tufano [1989]), and investment banks often enter new product lines by hiring away employees from competitors. ${ }^{12}$

At the market level, Smith (1986) points out that regulatory barriers to entry and exit are minimal or nonexistent and the identities of the top banks have changed considerably over time. ${ }^{13}$ Moreover, unlike commercial banks, investment banks are not constrained by their ability to raise deposits (see Boot and Thakor [2000]). And, as said, a large competitive fringe exists. Consequently, many find it difficult to argue that this market exhibits anticompetitive behavior. The coexistence of competitive and seemingly collusive features is well summarized by The Economist:

"No other business, investment bankers will assure you, is quite as brutally competitive as theirs. It is surely odd, then, that in America the fees investment banks charge to underwrite share offerings have not budged in more than a decade. In Britain, fixed undewriting fees are the subject of an antitrust investigation. [...] But how does this happen in an industry as intensely competitive as investment banking?"14

\subsection{Model sketch and main results}

As Aoki and Dinc (1997) point out, financiers will establish relationships only if they expect to obtain long-term rents. Among the mechanisms that can restrain price competition are regulations, ${ }^{15}$ frictions like informational monopolies, ${ }^{16}$ contracts, and self-enforcing norms. ${ }^{17}$ The previous discussion suggests that neither of the first three seem very relevant in restraining price competition in the investment banking market. On the other hand, many accounts of the industry suggest that price competition is restrained by informal unwritten rules. For example, in a colorful recent account of investment banking, Rolfe and Troob (2000, p.103), note that spreads have stayed high

" [...] because there has always been an unspoken agreement among the bankers that when it comes to underwritings they won't compete on price. The spreads are sacrosanct. He who cuts spreads will himself become an outcast [...]. The community of investment banks has always been small enough so that if one bank were to break

\footnotetext{
${ }^{11}$ See Hayes et al. (1983, Table 25). Matthews (1994, p.41) similarly observes that although "the securities industry has multiple lines of business, with different firms holding leadership positions in various lines ... (t)he national full-line firms compete against one another in virtually all securities lines of business."

${ }^{12}$ Yasuda (1999) finds that in the corporate bond underwriting market firms are willing to pay a premium to commercial banks with whom they have a relationship.

${ }^{13}$ Bloch (1989 p. 7) points out that more than half of the top investment banks in the 1950s were no longer major players in the 1980s (see also Matthews [1994, p. 160]).

14 "Investment Banking: Overcharging Underwriters" (June 27, 1998).

${ }^{15}$ See, for example, Hellmann et. al. (1997).

${ }^{16}$ See Besanko and Thakor (1983), Boot and Thakor (2000), Fischer (1990), Rajan (1992) and Sharpe (1990).

${ }^{17}$ See Aoki and Dinc (1997, s.3) for a discussion of these mechanisms.
} 
ranks on the pricing issue, the others would quickly join forces and squash the offender [...]. Every banker knows that the pricing issue is a slippery slope best avoided because once the price cutting begins, there's no telling where it will end."

Hence, we study a self-enforcing norm under which investment banks have incentives not to undercut each other ex post. We derive this norm from the relationship technology.

To do deals banks can use an arm's-length technology that is linear in deal volume; or a relationship technology. Each relationship is costly to set up but once established the marginal cost of doing deals is zero. Each firm has relationships with several investment banks, and other banks can free ride on these; that is, relationships are not exclusive and information is not excludable. ${ }^{18}$ Loose linkage between costs and fees implies that investment banks must pay the cost of establishing relationships but cannot directly charge for them.

Not surprisingly, in a one-period model relationships cannot be established. Once sunk costs are incurred, Bertrand competition drives fees below what is needed to recover them. When banks repeatedly interact, however, cooperation can be sustained. This occurs via a standard noundercutting condition: in equilibrium the gains from continued cooperation must outweigh the gains from undercutting to grab more deals. This condition not only indicates under which parameter values cooperation is sustainable; it also imposes restrictions on aggregate market structure.

As in any repeated game there are multiple equilibria. But using the strongest feasible punishment one can derive a lower bound on the fee and an upper bound on the number of investment banks such that cooperation is self-enforcing. The bounds show that relationships can exist in equilibrium even when they are neither exclusive nor excludable. Moreover, fees and concentration will be such that banks that establish relationships make profits in equilibrium even when entry is allowed. The reason: an investment bank can always make profits by undercutting and destroying cooperation. Hence, it will refrain from doing so only when cooperating is at least as profitable as undercutting. Entry will stop before eliminating profits because with too many banks, market shares are small, and undercutting becomes too attractive.

Changes in structural parameters affect the relationship-competition tradeoff. After a parameter change the bounds on the fee and the number of investment banks adjust, sometimes in surprising directions, to preserve the incentives to cooperate. To see the logic at work, consider an increase in the number of banks with whom firms have a relationship. Standard intuition maintains that this should make competition more intense, reduce fees and concentration, and undermine relationships. The no-undercutting condition shows, however, that this intuition is misleading. To preserve the incentives to cooperate, the fall in the probability of getting a deal conditional on

\footnotetext{
${ }^{18} \mathrm{~A}$ good is excludable if the owner can prevent others from using it at a very low cost. For a discussion, see Rosen (1992), pages 68-69.
} 
having a relationship can be undone either by fewer banks, so that the unconditional probability of winning a deal increases; or by higher fees. Thus, more intense competition for deals at the local level leads to an increase in concentration and the fee paid by firms.

Our analysis also sheds light on the competitive role of fringe banks. Sunk set-up costs imply that only firms with large enough volumes will establish relationships; small firms will be served by fringe banks. Unlike most models, however, segmentation occurs by relationship banks rationing firms - the cost structure implies that all firms, whether small or large, would like to do deals with relationship banks. Because of this, relationship and arm's-length markets are effectively separated. Changes in competitive conditions in the fringe segment will not affect the relationship segment; and, relationship banks make profits despite a competitive fringe of arm's-length banks.

Last, we also study nonprice competition (e.g. sales efforts), a common way of dissipating rents in industries with soft price competition. We find that sales efforts, or more generally, any aggregate sunk expenditures, cannot lead to profit dissipation because it would make continuing cooperation unprofitable. Nonprice competition has a somewhat surpising competitive implication, however: it imposes an upper bound on the fee that banks can charge. Fees that are too high weaken the incentives to punish a deviator who outspends competitors in sales effort, and are not sustainable in a long-run equilibrium. This mechanism may provide a competitive check on banks holding up firms after establishing relationships. ${ }^{19}$

\subsection{Relation with the literature on relationships and competition}

Our paper is directly related to Petersen and Rajan (1995) and Boot and Thakor (2000) who study relationships in the commercial banking market, and to Anand and Galetovic (2000). We build on their observation that there is a fundamental tradeoff between competition and the incentives to incur the sunk costs needed to establish relationships.

Petersen and Rajan (1995) study a two-period model with good and bad firms. There is asymmetric information in the first period since good and bad borrowers are observationally identical, but the bank becomes fully informed in the second period. Short term loans made in period 1 to borrowers with a low credit rating (i.e. a high probability of being bad) are not profitable because high interest rates induce moral hazard. These borrowers receive finance only if banks can charge a sufficiently large rate in the second period to those firms that reveal themselves to be good. Thus, banks are willing to establish relationships only if price competition is sufficiently soft in the second period. In their paper, the market structure that creates relation-specific rents is taken as given. We build on their work by endogenizing market structure and the source of rents.

In Boot and Thakor (2000) banks make both relationship and transaction (or arm's-length)

\footnotetext{
${ }^{19}$ The hold-up problem has been well recognized in the literature; see Sharpe (1990) and Rajan (1992).
} 
loans, and face competition from the capital market. Relationships add value to borrowers in proportion to the bank's sunk "sector specialization" investment. Banks are willing to make this sunk investment because it leads to ex post differentiation. Nevertheless, as more banks enter the market the intensity of ex post competition increases and there are fewer incentives to invest in sector specialization. A zero-profit entry condition endogenizes market structure.

There are three main differences between our model and theirs. First, as Boot and Thakor point out (p.683), local market power in commercial banking stems from the illiquidity of each loan due to its information sensitivity. ${ }^{20}$ By contrast, in investment banking, each firm establishes several relationships and switching costs are small because of nonexcludability. Consequently, in our model competition is softened by a self-enforcing norm, not by frictions. Second, and related, entry and market structure are governed by the self-enforcing norm, not by a zero-profit condition. Intermediaries can therefore make profits in equilibrium without inducing further entry. Third, like Boot and Thakor, we allow for both arm's-length and relationship technologies. But, unlike their model, the split of firms between relationship and arm's-length deals is determined by quantity rationing by banks (because of loose linkage), not by a price-indifference condition. Hence, a dual market structure emerges where competitive conditions in the arm's-length segment do not affect competition in the relationship segment. ${ }^{21}$

This paper is also related to Anand and Galetovic (2000), who analyze the determination of market structure when information is not excludable. Like that model, we study the implications of a self-enforcing norm for market structure. We depart by simultaneously studying several competitive features that characterize the investment banking market and are, in principle, inimical to relationships. These include non-exclusivity, nonprice competition, and competition from arm's-length transactions. By studying these features together with soft price competition in an integrated setting, we can reconcile the coexistence of competitive and seemingly collusive features of this industry, which has been noted by many observers.

Last, our paper is methodologically related to Dutta and Madhavan (1997) who study implicit collusion in broker-dealer markets. In their model, the collusive equilibrium rationalizes a striking series of practises which have been empirically documented, but collusion is not necessary for a broker-dealer market to exist. In our model, efficient relationships will not be established unless price competition is softened by a self-enforcing norm. Consequently, such a norm is sustainable in equilibrium even with free entry.

\footnotetext{
${ }^{20}$ See James (1987), Kang et al. (2000), Lummer and McConnell (1989), and Shockley and Thakor (1997).

${ }^{21}$ In Boot and Thakor (2000) firms can go to the capital market and banks can make both relationship and armslength loans. This allows them to study the interaction between commercial bank lending and the capital market. They show that stronger interbank competition reduces rents from arms-length loans proportionately more than those of relationship loans and thus favor the latter. However, stronger competition reduces rents of both types of loans and reduces the incentives to invest in sector specialization.
} 


\section{The model}

\subsection{Setup and motivation}

There are three types of agents: a continuum of firms of measure $f$ that want to do deals; $m$ identical and risk-neutral investment banks that can establish relationships and implement deals (henceforth we call these 'relationship banks'); and a large number of investment banks that can implement deals but cannot establish relationships (henceforth we call these 'fringe banks'). There is no loss of generality in excluding fringe banks from relationships, because $m$ can be easily endogenized.

Each firm is described by the deal size $s$ and number of deals $d$ it does in a given period, with $v \equiv s \cdot d$ denoting its total dollar volume of deals in any period. Volume $v$ is uniformly distributed in the interval $[0, \bar{v}]$, with density function $g(v)=\frac{1}{\bar{v}}$ and corresponding $\operatorname{cdf} G(v)=\int_{0}^{v} \frac{1}{\bar{v}} \mathrm{~d} u=\frac{v}{\bar{v}}$. Thus $f \cdot \frac{v}{\bar{v}}$ is the measure of firms whose deal volume during the period is at most $v$.

Deals can be implemented using two distinct technologies. The first is a relationship technology that is used only by relationship banks. To do deals with any firm using this technology a bank must incur a sunk cost $R$, which is independent of $s$ and $d$. Once $R$ is incurred, however, the bank can do any number of deals with the same firm at no additional cost. We further assume that firms that do deals with banks using this technology establish $k \geq 1$ relationships. Following Eccles and Crane (1988) we call this the firm's "group of $k$ core banks". We assume without loss of generality that $k$ is exogenous and the same for all firms. ${ }^{22}$

Notice three features of the relationship technology. First, it involves sunk costs to acquire information about the firm; this information can be thought of as a transactor- or relationshipspecific asset (see Williamson [1979]). James (1992) presents evidence suggesting that the information gathered by an investment bank about a particular firm can be reused in another deal. Second, $R$ is paid by the investment bank, not the firm. These two features imply that there is a 'loose linkage' between the costs incurred by a bank and the fees it generates from deals. Third, relationships are not exclusive, that is $k>1$. Thus, a bank in a firm's core group is not guaranteed its business.

A linear "arm's-length" technology enables any bank, relationship or fringe, to implement a deal without having a relationship. There are no sunk costs incurred when using this technology, but firms incur transaction costs. The magnitude of these transaction costs depend on whether the firm has a group of $k$ core banks, and the type of bank it transacts with. Specifically:

- When the firm has a group of $k$ core banks, then implementing a deal with a non-core relationship bank imposes a transaction cost $\alpha v$, with $\alpha \in\left[0, \frac{R}{\bar{v}}\right)$ (that is, $\alpha$ is "small"). On the other

\footnotetext{
${ }^{22}$ Detragiache et al (2000) study a model where a firm optimally chooses the number of relationships with commercial banks. Unlike our model, relationship costs are not sunk but fixed, and any bank recovers all relationship costs regardless of the amount it lends. For that reason, Bertrand competition does not undermine relationships.
} 
hand,a deal implemented by a fringe bank imposes a transaction cost $\beta v$, with $\alpha<\beta<1$.

- When the firm does not any core banks, then implementing the deal with any bank, fringe or relationship, imposes a transaction cost $\beta v$ on the firm.

In either case, we assume for simplicity that the bank does not incur any transaction cost when using the arm's-length technology.

The assumption that doing a deal with a non-core bank imposes an additional transaction cost on the firm captures the fact that the information and knowledge gathered in a relationship are useful in designing the right deal structure (see Eccles and Crane [1988] for an elaborate account). ${ }^{23}$ This transaction cost is proportional to deal size because the costs of erring in the correct deal structure should be increasing in the size of the deal. The assumption that $\alpha<\beta$ and small, is made because the information gathered by core banks is at least partially non excludable and can be used by other relationship banks. For example, part of it resides in the human capital of individuals who can move from one relationship bank to another (see Anand and Galetovic [2000]) or ideas can be copied (see Tufano [1989]).

\subsection{Time line and equilibrium in the one-period game}

We now rigorously describe the timing of actions, and then characterize the equilibrium of the one-period game. The time line is as follows:

1. Each firm randomly contacts $k$ relationship banks.

2. Each bank chooses those firms with which it wants to establish relationships, and incur the corresponding sunk cost $R$. If $k$ banks establish relationships with a given firm, then that is the core group of banks of the firm.

3. Firms announce deals.

4. (Fee offers) Each relationship bank $i$ simultaneously makes a price offer $\lambda_{i}^{c} \in[0,1] \cup\{\infty\}$ to all firms with whom it has a relationship, an offer $\lambda_{i}^{n c} \in[0,1] \cup\{\infty\}$ to all firms in a core group that does not include $i$, and an offer $\lambda_{i}^{n r} \in[0,1] \cup\{\infty\}$ to firms that have no relationships (superscript ' $c$ ' stands for 'core', superscript ' $n c$ ' for 'non core' and superscript ' $n r$ ' for 'no relationship'). These offers are expressed as a fraction of deal volume (thus, they represent commissions or percentage fees). $\lambda=\infty$ means that no offer was made. Obviously $\lambda_{i}^{c}=\infty$ if bank $i$ is in no core group and $\lambda_{i}^{n c}=\infty$ if it has a relationship with every firm.

Simultaneously, each fringe bank $j$ makes a price offer $\lambda_{j}^{f} \in[0,1] \cup\{\infty\}$ to all firms.

\footnotetext{
${ }^{23}$ Yasuda (1999) also finds that in corporate bond underwriting, firms are willing to pay a premium to banks with whom they have had a relationship.
} 
5. Each firm chooses the bank offering the lowest fee net of transaction costs. If $x>1$ banks tie, then each bank wins the deal with probability $\frac{1}{x}$.

6. Deals are implemented, fees paid and the game ends.

To define bank strategies let $\mathcal{H}$ be the set of possible histories right before banks make fee offers. A strategy by a relationship bank $i$ is a tuple $\left(\mathcal{R}_{i}, \Lambda_{i}\right)$. $\mathcal{R}_{i}:[0, \bar{v}] \rightarrow\{0, R\}$ is a function that indicates whether bank $i$ will establish a relationship with those firms that selected $i$ to form part of the core group. Since firms are completely described by $v$, bank $i$ 's decision can be conditioned on firm type. $\Lambda_{i}=\left[\lambda_{i}^{c}, \lambda_{i}^{n c}, \lambda_{i}^{n r}\right]$ is a three-dimensional vector function $\Lambda_{i}: \mathcal{H} \rightarrow[[0,1] \cup\{\infty\}]^{3}$. In turn, a strategy by fringe bank $j$ is a function $\lambda_{j}^{f}: \mathcal{H} \rightarrow[0,1] \cup\{\infty\}$. Proposition 3.1 characterizes the set of subgame perfect equilibria of this game. (See Appendix A for a strategy combination that is a subgame perfect equilibrium of the one-period game.)

Proposition 3.1. In any subgame perfect equilibrium, no relationships are established and $\lambda^{f}=0$.

Proof. Suppose, by way of contradiction, that bank $i$ establishes a relationship with a firm. Suppose first that $k>1$. In any subgame with relationships, Bertrand competition for deals between core banks drives $\lambda^{c}$ to 0 in equilibrium. On the other hand, if $k=1$, Bertrand competition with relationship banks drives $\lambda^{n c}$ to $\alpha$, and hence $\lambda_{i}^{c}$ to $\alpha<\frac{R}{\bar{v}}$ in equilibrium in any subgame where bank $i$ is the firm's only relationship bank. Hence, in both cases bank $i$ loses money if it becomes a relationship bank, therefore $\lambda_{i}^{c}=\infty$. Finally, note that since there are no variable cost of doing deals, Bertrand competition among fringe banks drives $\lambda^{f}$ to 0 in equilibrium.

Hence no relationships are established in equilibrium, only banks that do not establish relationships are active, and each deal costs $\beta s$ to firms. Moreover, since there are no variable costs of doing deals, fees are driven to zero in equilibrium. For firms with $v$ such that $\beta \leq \frac{k R}{v}$ (i.e. firms that do small and infrequent delas) this equilibrium is efficient. By contrast, firms with $v$ such that $\beta>\frac{k R}{v}$ would want to establish $k$ relationships and compensate banks for the incurred sunk costs. This can be summarized in the following result:

Result 3.2. The equilibrium of the one-shot game is efficient form firms that do infrequent or small deals. It is inefficient for firms that do large or frequent deals.

A straightforward implication of Result 3.2 is that low-volume firms will never establish relationships. Moreover, Result 3.2 shows that establishing relationships is not efficient for every type of client. Firm volume will determine which technology is efficient. 


\section{The structure of investment banking markets}

The previous section suggests that investment banks will establish relationships only if they anticipate that they will not be undercut. In this section we show that when relationship banks repeatedly interact, a self-enforcing norm that softens price competition can sustain relationships. In this equilibrium, relationship banks do not undercut each other and fees are high enough to pay for the sunk relationship costs.

We assume that banks are infinitely lived with discount factor $\delta \in\left(\frac{k-1}{k}, 1\right)$. They play the one-period game an infinite number of times, but each generation of firms lives only one period.

We study a symmetric subgame perfect equilibrium where all relationship banks charge the same fee $\lambda^{c}>0$ period after period, all fringe banks compete and charge $\lambda^{f}=0$, and relationships are profitable. As is well known, any repeated game will exhibit many equilibria (see Fudenberg and Maskin [1986]), so that one cannot hope to obtain sharp predictions on the outcomes that will emerge. But, as Sutton $(1991,1997)$ has shown in a different context, it is useful to characterize the bounds on the variables under study, here market shares, concentration, and fees.

We proceed as follows. First we characterize stationary equilibria where any undercutting destroys cooperation forever; that is, we consider equilibria with the strongest feasible punishment (in the one-period game the Nash and minmax payoffs coincide because any bank can guarantee itself an average payoff of at least zero by doing nothing). Next we derive bounds on market shares, concentration and fees such that relationships are profitable, and explore some comparative equilibria implications of the model. Last, we characterize market structure. In Appendix A we rigorously construct a subgame perfect equilibrium that induces this outcome.

In what follows, it is important to use a precise definition of 'undercutting':

Definition 4.1. Let $\lambda^{c}$ be the fee charged in an equilibrium with relationships. Then there is undercutting in period $t$ if $\min \left\{\lambda_{i}^{c}(t), \lambda_{i}^{n c}(t)+\alpha\right\}<\lambda^{c}$ for at least some $i$.

Note that $\lambda^{n r}$ and $\lambda^{f}$ are not part of the definition. We are assuming that neither "undercutting" in the fringe segment, nor fringe banks setting fees such that $\lambda^{f}+\beta<\lambda^{c}$, destroys cooperation.

\subsection{Market structure}

In this subsection we obtain lower bounds on market shares, concentration and fees. The analysis centers around a standard 'no undercutting' inequality which states conditions under which price norms among relationship banks are self-enforcing.

First we obtain the segment of firms that will be served by relationship banks. Consider an equilibrium where all relationship banks offer $\lambda^{c}$. Since each firm's core group contains $k$ 
relationship banks, each bank in that group wins a given deal with probability $\frac{1}{k}$. Therefore, banks will establish relationships only with those firms such that

$$
\frac{1}{k} \lambda^{c} v-R \geq 0
$$

This sets a lower bound $\underline{v}=\frac{k R}{\lambda^{c}}$ (note that since $\lambda^{c} \leq \beta$ in equilibrium, all firms would like to establish relationships). It follows that the measure of firms that establish relationships is $f \cdot\left(\frac{\bar{v}-\underline{v}}{\bar{v}}\right) \equiv f^{r}$, the total volume of deals intemediated by relationship banks is $f \cdot \int_{\underline{v}}^{\bar{v}} \frac{\underline{v}}{\bar{v}} \mathrm{~d} v=$ $f \cdot\left(\frac{\bar{v}^{2}-\underline{\underline{v}}^{2}}{2 \bar{v}}\right)=f^{r} \cdot\left(\frac{\underline{v}+\bar{v}}{2}\right)$, and the average size of a deal done by relationship banks is $V=\frac{\underline{v}+\bar{v}}{2}$.

We are now ready to obtain the no-undercutting condition. Each period relationship banks compare the long run gains from cooperating against the one-time gains of undercutting to significantly increase their market share. Lets start by computing the gains from cooperation. Bank $i$ will compete for deals with $k-1$ other banks in each core group in which it is a participant. Thus bank $i$ will make deals of value $\frac{V}{k}$ on average. Each firm will pay $\frac{\lambda^{c} V}{k}$ in fees on average and total costs will be $R$ per firm, regardless of the number of deals done. Hence, profits per firm are $\frac{\lambda^{c} V}{k}-R$ on average. If bank $i$ has relationships with a fraction $\eta_{i}$ of all $f^{r}$ firms that establish relationships (with $\eta_{i} \in[0,1]$ and $\sum_{j=1}^{m} \eta_{j}=k$ ), ${ }^{24}$ its long-run profits from period $t+1$ on are

$$
\frac{\delta}{1-\delta} f^{r} \eta_{i}\left(\frac{\lambda^{c} V}{k}-R\right)
$$

The short-run gains from undercutting are obtained as follows. By setting $\lambda_{i}^{c}$ slightly below $\lambda^{c}$, bank $i$ can get an additional $\left(1-\frac{1}{k}\right) \lambda^{c} V$ on average from each firm in whose core group $i$ is. Moreover, by setting $\lambda_{i}^{n c}$ slightly below $\lambda^{c}-\alpha$, bank $i$ can win deals from the remaining $\left(1-\eta_{i}\right) f^{r}$ firms with whom it does not have a relationship, thus obtaining slightly less than $\left(\lambda^{c}-\alpha\right) V$ per firm. This destroys cooperation, but yields a one-time gain a shade below

$$
f^{r}\left[\eta_{i}\left(1-\frac{1}{k}\right) \lambda^{c}+\left(1-\eta_{i}\right)\left(\lambda^{c}-\alpha\right)\right] V .
$$

Therefore, the no-undercutting condition reads:

$$
\frac{\delta}{1-\delta} f^{r} \eta_{i}\left(\frac{\lambda^{c} V}{k}-R\right) \geq f^{r}\left[\eta_{i}\left(1-\frac{1}{k}\right) \lambda^{c}+\left(1-\eta_{i}\right)\left(\lambda^{c}-\alpha\right)\right] V .
$$

For future reference it is useful to note that when all banks establish relationships with the same

\footnotetext{
${ }^{24}$ Note that $\eta_{i}$ is not a market share. Bank $i$ may have a relationship with all firms and yet not be a monopoly, since each firm has relationships with $k$ banks. There is a direct relation between $\eta_{i}$ and $i$ 's market share, however. If on average banks get a fraction $\frac{1}{k}$ of deals made by firms with whom they have a relationship, bank $i$ will make a fraction $\mu_{i} \equiv \frac{\eta_{i}}{k}$ of all deals, with $\sum_{j=1}^{m} \mu_{j}=1$. Thus, $\mu_{i}$ is bank's $i$ market share.
} 
number of firms, $\eta_{i}=\frac{k}{m}$. Then, condition (4.1) can be rewritten as

$$
\frac{\delta}{1-\delta} \frac{f^{r}}{m} k\left(\frac{\lambda^{c} V}{k}-R\right) \geq \frac{f^{r}}{m}\left[(m-1) \lambda^{c}-(m-k) \alpha\right] V
$$

Contrary to similar inequalities in standard oligopoly models, (4.1) is a precondition for the existence of relationship banks; otherwise, sunk costs cannot be recovered. For this reason, it can be shown that cooperation between relationship banks is robust to entry, i.e., that employing relationship technologies is sustainable (see Anand and Galetovic [2000]). Moreover, because these inequalities are a necessary condition for the existence of the market, they restrict observable market structures as well. We now explore the implications of these restrictions.

Market power As long as condition (4.1) holds, price norms are self-enforcing. This in spite of the fact that each firm has relationships with several banks. Thus:

Result 4.2. Relationships can exist even if relationship banks are not local monopolies.

While banks need not be local monopolies, inequality (4.1) implies that each bank must establish relationships with a sufficiently large fraction of firms. Only then will the gains from continued cooperation outweigh those of undercutting. Thus, condition (4.1) generates a rationale for big banks. But, at the same time, banks cannot be too large. The reason is that if a few banks grab all relationships, it becomes profitable for the remaining banks to undercut, because the value of continued cooperation dwindles. Thus, straightforward manipulation of (4.1) yields both a lower and an upper bound on $\eta_{i}$, and, therefore, on $i$ 's market share $\mu_{i} \equiv \frac{\eta_{i}}{k}$. This implies that:

Proposition 4.3. Relationships will be established only if there are a few investment banks with similar market shares.

Proof. Fix the equilibrium number of banks, $m$. Then:

$$
\underline{\eta} \leq \eta_{i} \leq k-(m-1) \underline{\eta}
$$

where

$$
\underline{\eta}=\frac{\left(\lambda^{c}-\alpha\right) V}{\left(\lambda^{c}-\alpha\right) V+\frac{\delta}{1-\delta}\left(\frac{\lambda^{c} V}{k}-R\right)-\left(1-\frac{1}{k}\right) \lambda^{c} V}<1 .
$$

Since $\mu_{i} \equiv \frac{\eta_{i}}{k}$, condition (4.3) also imposes a lower and upper bound on market shares:

$$
\underline{\mu} \leq \mu_{i} \leq 1-(m-1) \underline{\mu} .
$$

It is straightforward to see that the upper bound on $\mu_{i}$ must be less than 1 . 
Proposition 4.3 implies that relationship banks must be large and of similar size. It also implies that:

Result 4.4. Aggregate monopoly power is not necessary for firms to establish relationships. In fact, cooperation is not feasible with a dominant relationship bank.

Results 4.2 and 4.4 and Proposition 4.3 show the relation between local and aggregate market structure. Relationships can survive only if there is no price competition at the local level. However, this restricts aggregate market structure.

Concentration and fees Condition (4.5) implies that there must be a maximum number of relationship banks in the market, or (what amounts to the same) a lower bound on concentration. It can be easily seen from condition (4.5) that this bound is reached when all relationship banks have the same market share, in which case both the lower and upper bounds on $\mu_{i}$ coincide. Then, straightforward manipulation of condition (4.2) shows that for a given fee $\lambda^{c}$, the number of relationship banks $m$ cannot exceed

$$
\bar{m} \equiv \frac{k}{\underline{\eta}}=\frac{1}{\lambda^{c}-\alpha}\left[\frac{1}{1-\delta} \lambda^{c}-\left(\alpha+\frac{\delta}{1-\delta} \frac{R}{V}\right) k\right]
$$

Note that we derived the bound $\bar{m}$ assuming that relationship banks use the strongest feasible punishment. It can be shown that any weaker punishment can sustain cooperation only if the number of banks is less than $\bar{m}$ (see Anand and Galetovic [2000]). Hence the upper bound on the number of relationship banks $\bar{m}$ is independent of the punishment used.

Next we characterize the relation between this lower bound on concentration and the intensity of price competition. To do this, substitute $\bar{m}$ into condition (4.2), let it hold as an identity, and totally differentiate with respect to $\lambda^{c}$ and $\bar{m}$. Rearranging yields

$$
\frac{\mathrm{d} \bar{m}}{\mathrm{~d} \lambda^{c}}=\frac{1}{\lambda^{c}-\alpha}\left\{\left[\frac{\delta}{1-\delta}-(\bar{m}-1)\right]\left(1-\varepsilon_{V, \lambda}\right)-\frac{\alpha}{\lambda^{c}}(\bar{m}-k) \varepsilon_{V, \lambda}\right\}
$$

where $\varepsilon_{V, \lambda}=\frac{\underline{v}}{\bar{v}+\underline{v}} \leq \frac{1}{2}$ is the elasticity of the average volume per firm with respect to $\lambda^{c}{ }^{25}$ Hence, if $\alpha$ is sufficiently small (i.e. information is not a private good), then $\frac{\mathrm{d} \bar{m}}{\mathrm{~d} \lambda}>0$. That is, tougher price competition leads to more concentration. Thus, nonexcludability implies:

Result 4.5. Lower fees can be sustained only in a more concentrated market.

\footnotetext{
${ }^{25}$ For the derivation of (4.7) see Appendix B.
} 
To see the intuition, suppose that $\alpha=0$. Then, straightforward manipulation of the noundercutting condition (4.2) yields

$$
\frac{\lambda^{c} V-k R}{\lambda^{c} V}=\frac{1-\delta}{\delta}(\bar{m}-1)
$$

This says that when the fee $\lambda^{c}$ falls, profits from continued cooperation, $\lambda^{c} V-k R$, fall proportionately more than profits from undercutting, $\lambda^{c} V$. Hence, the number of intermediaries must be smaller to preserve the incentives not to undercut. Consequently, the lower are fees, the smaller is the number of intermediaries that can be sustained in a cooperative equilibrium.

The dual of $\bar{m}$ is a lower bound on the fee, call it $\underline{\lambda}^{c}$. For a given $m$, fees which are lower than $\underline{\lambda}^{c}$ would make undercutting profitable. ${ }^{26}$ Thus, the lower bound on $\lambda^{c}$ can be obtained after straightforward manipulation of (4.6), and equals

$$
\underline{\lambda}^{c}=\frac{\frac{\delta}{(1-\delta)} \frac{k R}{V}-\alpha(m-k)}{\frac{1}{1-\delta}-m} .
$$

Since there must be at least $k$ banks in the market, the lowest feasible fee $\underline{\lambda}^{c}$ is given by:

$$
\frac{\delta}{1-(1-\delta) k} \frac{k R}{V}
$$

Now, $k>1$, therefore $\delta /[1-(1-\delta) k]>1$, and $\underline{\lambda}^{c}$ always exceeds average costs $\frac{k R}{V}$. Thus:

Result 4.6. Relationship banks make profits in equilibrium.

Result 4.6 makes clear the departure from average cost pricing. The intuition is that pricing is not determined by a zero profit condition here, but by a no-undercutting condition. The result then follows directly from the fact that a relationship bank can always earn profits by unilaterally undercutting. Consequently, income from fees must exceed relationship costs $R$.

Note that relationships do not create market power and therefore are not an intrinsic source of rents. Rather, rents stem from the self-enforcing norm which endogenously creates market power and, in turn, makes relationships feasible.

Now, how do fringe banks compete with relationship banks? Recall that the arm's-length technology exhibits constant returns to scale. Hence, Bertrand competition means that:

\footnotetext{
${ }^{26}$ To see this, note from the no ex post undercutting condition (4.1) that a higher fee will make it easier to sustain cooperation if and only if

$$
\frac{\delta}{1-\delta} \frac{\eta_{i}}{k}>1-\frac{\eta_{i}}{k}
$$

Since $\eta_{i} \geq \underline{\eta}$, it follows that a sufficient condition for this inequality to hold is that $\frac{\delta}{1-\delta} \frac{\eta}{\bar{k}}>1-\frac{\eta}{\bar{k}}$. Substituting $\underline{\eta}$ for expression (4.4) and recalling that $\alpha<\frac{R}{V}$, one can establish that this is in fact the case.
} 
Result 4.7. In equilibrium, $\lambda^{f}=0$ and $\lambda^{c} \leq \beta$.

In other words, competition from fringe banks sets an upper bound on the fees that relationship banks can charge.

Figure 4 summarizes the previous results. $\mathcal{L}$ is the set of pairs $\left(\lambda^{c}, m\right)$ such that condition (4.1) is satisfied. $\lambda^{c}$ cannot exceed $\beta$ because firms would switch to fringe banks. At the same time, locus $\mathrm{CC}$ traces the maximum number of relationship banks, $\bar{m}$, for any given admissible fee $\lambda^{c}$; or conversely, the lower bound on the fee, $\underline{\lambda}^{c}$, for any admissible number of relationship banks.

The positive relation between fees and the number of banks shown by locus CC seems to run counter to standard oligopoly models, where typically prices are higher in more concentrated markets. Yet the difference is more apparent than real. The intuition in standard models comes from studying what happens to prices when concentration exogenously changes. In such models, however, equilibrium entry and concentration is determined by a zero-profit condition that tells a story similar to 4.7's: the softer is price competition, the more concentrated will be the market in equilibrium (see Sutton [1997]). A distinctive feature of the model we have presented is that a zero profit condition need not be binding. And, not much can be said about fees, because these are determined independently of $m$.

\subsection{Dual market structure}

Except for setting an upper bound on the fee that relationship banks can charge, fringe banks were ignored in the previous subsection. We now show that this separation is warranted.

Since $\lambda^{c} \leq \beta$, one might ask why any firm would do deals with a fringe bank. The reason is that, as we saw before, firms with volume lower than $\underline{v}$ do not generate enough fee revenue to compensate banks for incurring the sunk cost $R$ of establishing relationships. Hence, low volume firms are rationed out of the relationship banking segment.

A key implication of rationing is that whether a firm is served by a relationship or a fringe bank is not determined by a standard indifference condition - as long as $\lambda^{c}<\beta$, firms served by a fringe bank would clearly prefer to be served by a relationship bank. Hence, marginal changes in parameters in, say, the fringe segment of the market will not affect firms' decisions about which type of bank to transact with. This is why one can appropriately claim that the relationship segment and the fringe segment are two different markets.

Notice that fringe banks cannot compete for the business of high-volume firms because charging $\lambda^{c}$ or less would make them lose money. And, relationship banks do not want to serve low-volume firms. Therefore, competition among banks cannot integrate the two segments of the market. ${ }^{27}$ An

\footnotetext{
${ }^{27}$ The only effect of changes in parameters in the relationship segment is to change the cutoff volume $\underline{v}$. Hence, such parameter changes affect the relative size of the segments, but not prices in the other segment.
} 
implication is that our result concerning excess rents in the relationship segment continues to hold:

Result 4.8. Relationship banks obtain excess rents even in the presence of a competitive fringe.

Note that our model does not restrict the structure of the arm's-length segment. Beyond competitive pricing, there is no lower bound on concentration, and market shares of banks are indeterminate. At the same time, there is a distinct prediction on the size distribution of firms in each segment. On the one hand, a concentrated banking market that serves firms which make large and frequent deals; on the other hand, a competitive banking market that serves firms which make small and infrequent deals. Thus, in contrast to the usual way of looking at this as one market, these are more appropriately viewed as two distinct markets - a "dual" market structure.

Which assumptions are driving these results? Nothing hinges on the assumption that fringe banks cannot establish relationships. To see this, suppose that all banks were endowed with both technologies. A bank's decision of whether to establish a relationship with a given firm would still depend only on its deal volume. Moreover, the maximum number of banks active in the relationship segment would still be constrained by the no-undercutting condition. Last, rents in the arm's-length segment would be driven to zero by competition, just as in the present case. ${ }^{28}$

To obtain separation between the relationship and arm's-length segment, one needs to assume that the cost of establishing a relationship is sunk, is independent of firm volume, and is loosely linked to fees collected from deals. If banks could directly charge a firm for establishing a relationship - that is, the loose linkage assumption no longer holds - then a relationship would be priced at $R$. In that case, a firm with volume $v$ would establish a relationship only if $k R \leq \beta v$. Therefore, a firm with $v=\frac{k R}{\beta}$ would be indifferent between either type of bank. Contrary to the case of loose linkage, the indifference condition links prices, and thereby integrates both segments.

To see this, consider the case where, for some reason, relationship banks had market power, and could therefore extract rents from firms by charging $P>R$. In that case, the existence of an arm's-length segment would cause all firms with $v \leq \frac{k P}{\beta}$ to switch from relationship banks, thus tempering their market power. ${ }^{29}$ Notice also that regardless of the relative efficiency of the arm's-length technology, some firms will always find it attractive to switch. Neither of these results obtain in our model.

\footnotetext{
${ }^{28}$ In fact, cross-subsidization of the arm's-length segment from profits made in the relationship segment cannot occur as long as the no-undercutting condition is binding. Rents in the relationship segment are necessary to preserve the incentives to establish relationships.

${ }^{29}$ As a concrete example, assume that a monopolist relationship bank chooses $P$ to maximize profits. Then, one can easily show that with $v$ uniformly distributed over $[0, \bar{v}]$, the optimal monopoly price equals $\frac{1}{2}\left(\frac{\beta}{k} \bar{v}-R\right)$. Note that as $\beta$ falls, so does the price set by the relationship bank.
} 


\subsection{Comparative equilibria}

We have shown in the previous subsection that fringe and relationship banks serve different markets. Consequently, we can analyze the effect of changes in parameters on the equilibrium in the relationship market while ignoring fringe banks. The derivatives describe how the bounds of the relevant variables vary with exogenous parameters.

Market structure and market size Standard theory suggests that concentration should fall as market size increases because entry costs and scale economies become less important (see Sutton [1991]; Mas Collel et al. [1995, ch. 12] for a rigorous proof of this assertion). However, the noundercutting condition (4.1) suggests a different story. Note that all terms in that equation are multiplied by $f^{r}$, the number of firms that establishes relationships. When this number increases, i.e., as the size of the market increases, both the gains from cooperation and of undercutting increase in the same proportion. Any combination $\left(\lambda^{c}, m\right)$ satisfying condition (4.1) in the smaller market will also satisfy it in the larger market. Hence:

Result 4.9. Ceteris paribus, an increase in market size $f$ will have no effect on concentration.

An implication of Result 4.9 is that the lower bound on concentration does not fall with market size. Together with Result 4.3 on market shares, this implies that scale economies at the market level do not drive high concentration and large banks; ${ }^{30}$ instead, local sunk costs do.

Result 4.9 also stresses the central role of nonexcludability in determining aggregate market structure. If $\alpha$ were close to $\lambda^{c}$ then all that would be needed to sustain relationships is cooperation at the local level, and there would not be any implications for aggregate market structure. Hence, local sunk costs affect aggregate market structure only if relationships are not excludable.

Note that when setup costs are not sunk or relationships are excludable, concentration can still be due to scale economies at the aggregate level. Nevertheless, these scale economies would become less important with market size and Result 4.9 would no longer hold. Hence, Result 4.9 is a testable prediction of the model.

Switching costs and market structure The incentive to undercut exists not only for core banks, but also for non-core relationship banks. We now examine what happens to market structure and prices when a firm's cost of switching to a non-core relationship bank $(\alpha)$ increases.

\footnotetext{
${ }^{30}$ A similar result obtains in Sutton's (1991) theory of endogenous sunk costs. This result, together with lower bounds on concentration, obtains here even though sunk costs $R$ are exogenous. The reason is that the exogenous cost is incurred at the local level only and, as a result, the aggregate technology exhibits constant returns to scale. Hence, sunk costs are naturally "escalated" when the size of the market and the number of firms increases.
} 
When $\alpha$ increases, the gains from undercutting fall because non-core banks need to discount their fees by a larger amount to compete with core banks. Then, cooperation remains attractive even when fees fall. To confirm this intuition, totally differentiate (4.8) and rearrange to obtain:

$$
\frac{\mathrm{d} \underline{\lambda}^{c}}{\mathrm{~d} \alpha}=-\frac{(m-k) \alpha}{\left[\frac{\delta}{1-\delta}-(m-1)\right]\left(1-\varepsilon_{V, \lambda^{c}}\right)-\frac{\alpha}{\lambda^{c}}(m-k) \varepsilon_{V, \lambda^{c}}},
$$

which is negative as long as the no-undercutting locus $C C$ derived from (4.1) is upward sloping. Hence, when $\alpha$ increases, locus $C C$ shifts rightwards (see Figure 5). Similarly,

$$
\frac{\mathrm{d} \bar{m}}{\mathrm{~d} \alpha}=\frac{\bar{m}-k}{\lambda^{c}-\alpha}>0
$$

Result 4.10. When switching costs from core to non-core banks increases, fees tend to be lower for a given number of banks $m$. Conversely, concentration falls for a given fee $\lambda^{c}$.

Moreover, if $\alpha$ increases from $\alpha^{\prime}$ to $\alpha^{\prime \prime}>\alpha^{\prime}$ then $\mathcal{L}\left(\alpha^{\prime}\right) \subset \mathcal{L}\left(\alpha^{\prime \prime}\right)$. Therefore, cooperation is easier to sustain when competition from non-core banks is less intense.

Result (4.10) appears counterintuitive because switching costs are thought to increase market power. But in this model, concentration counters free-riding. Higher switching costs moderate free-riding, making relationships closer to an excludable good. Hence the need for market power diminishes.

Multiple relationships Assume that $k$ increases, so that firms establish relationships with more banks. To study the equilibrium effects on fees, substitute $\underline{\lambda}^{c}$ into condition (4.2), let it hold as an identity, and totally differentiate with respect to $\underline{\lambda}^{c}$ and $k$ (see Appendix B for the details of the derivation). Rearranging yields

$$
\frac{\mathrm{d} \underline{\lambda}^{c}}{\mathrm{~d} k}=\frac{\left.[(m-1)] \lambda^{c}-(m-k) \alpha\right] \frac{\bar{v}}{2 k}+\alpha V+\frac{\delta}{1-\delta} \lambda^{c} \frac{\bar{v}}{2 k}}{\left\{\left[\frac{\delta}{1-\delta}-(m-1)\right]\left(1-\varepsilon_{V, \lambda}\right)+\frac{\alpha}{\lambda}(m-k) \varepsilon_{V, \lambda}\right\} V},
$$

where we used that $\frac{\partial V}{\partial k}=\frac{\underline{v}}{2 k}$. This derivative is positive (again, see Appendix B), which implies:

Result 4.11. For a given number of banks, $m$, fees tend to be higher when firms establish more relationships.

Multiple relationships are often thought to toughen price competition. Result 4.11 runs counter to this intuition. While the analysis confirms that the effect of an increase in $k$ is to reduce the probability of winning a deal, and therefore the net margin per firm to each bank, $\frac{\lambda^{c} V}{k}-R$, it 
shows that the gains of unilaterally undercutting also increase. Thus, given $m$, each bank wants to establish relationships only if fees increase. ${ }^{31}$ Similarly,

$$
\frac{\mathrm{d} \bar{m}}{\mathrm{~d} k}=-\frac{\left[(m-1) \lambda^{c}-(m-k)\right] \frac{v}{2 k}+\alpha V-\frac{\delta}{1-\delta}\left(\lambda^{c} \frac{v}{2 k}-R\right)}{\left(\lambda^{c}-\alpha\right) V},
$$

which is negative. As can be seen from Figure 6 , an increase in $k$ reduces $\mathcal{L}$, the set of pairs $(\lambda, m)$ that can be sustained in equilibrium.

An increase in $k$ will, for a given $\lambda^{c}$, not just affect the concentration of banks in the relationship segment of the market, but the size of the relationship segment itself. To see this, note that the lower bound $\underline{v}$ on firm volume, $k R / \lambda^{c}$, increases in $k$. This will both reduce the number of firms that establish relationships with banks, $f^{r}$, and the aggregate volume of deals intermediated by relationship banks, $f^{r} \cdot \frac{\underline{v}+\bar{v}}{2}$. Thus, the effect of firms establishing more relationships is to increase concentration of relationship banks on the one hand, while increasing the market size served by the competitive fringe on the other. ${ }^{32}$ This apparent increase in both competition and concentration can explain why the effects of such changes may appear puzzling to observers.

All the results in this section stress the importance of analyzing changes in market conditions within an equilibrium framework, not limiting the analysis to the local firm-bank level. Market equilibrium requires adjustments at the aggregate level in fees or market concentration to preserve the incentives to incur the local sunk costs of relationships.

\section{Nonprice competition}

Investment banks compete in various nonprice dimensions. They incur sales expenditures, advertise, provide "free" advice on other financial and investment matters, and even price some services below their cost in order to get access to clients. One might ask how the results of the previous section change once we allow for nonprice competition. In particular, might nonprice competition dissipate the rents that banks get in equilibrium? In this section, we extend our model to include nonprice competition among banks, and show that banks still make excess profits. But, the "competition for deals" does restrain bank market power in that it imposes an upper bound on the fee $\lambda^{c}$ that banks can charge in equilibrium.

To allow for nonprice competition we must first alter the mechanism by which relationship banks contact firms in the first stage of the one-period game. Instead of a random allocation, we

\footnotetext{
${ }^{31}$ This result is consistent with the finding of Petersen and Rajan (1994) that small firms who borrow from more than one commercial bank pay higher interest rates on average.

${ }^{32}$ Boot and Thakor (2000) find a somewhat similar result in the context of commercial bank relationships. They argue that the effect of increased interbank competition on relationship lending by commercial banks includes both a negative absolute effect on volume of loans lent through relationships but a positive relative (substitution) effect on the capacity devoted by banks to relationship lending.
} 
now assume that at the beginning of each period, each relationship bank spends a total amount $\mathcal{E}_{i} \equiv f^{r} E_{i}$ in 'sales effort' to contact firms. Sales efforts result in contacts with firms according to the following assumptions:

Assumption 5.1. (i) A relationship bank must spend at least $\underline{\mathcal{E}}=f^{r} \underline{E}$ as its total amount in sales effort to contact firms.

(ii) Firms contact relationship banks who have spent the $k$ 'th highest amounts in sales effort. If $y>1$ banks spend the $k$ th highest amount, then each bank contacts a firm with probability $\frac{1}{y}$.

(iii) If fewer than $k$ banks spend $\underline{\mathcal{E}}$ or more, then firms contact no bank.

It will be useful to number relationship banks according to their sales effort and adopt the following notational convention: $\mathcal{E}_{1} \geq \mathcal{E}_{2} \geq \ldots \geq \mathcal{E}_{k} \geq \ldots \geq \mathcal{E}_{m}$. That is, relationship bank 1 spends the (weakly) largest amount in sales effort. Note that according to this convention $\mathcal{E}_{k}$ is by definition the (possibly not unique) $k$ th highest sales effort.

Assumption 5.1 may seem extreme because it makes sales efforts redundant if a bank spends a shade less than $\mathcal{E}_{k}$. As we will see below, however, this extreme assumption (on how sensitive are contacts to changes in sales effort) entails no loss of generality because it tilts the results towards obtaining a higher upper bound on $\lambda^{c}$.

We now study a symmetric equilibrium where all relationship banks spend $\mathcal{E} \geq \underline{\mathcal{E}}$ (in Appendix $\mathrm{C}$ we rigorously construct strategy combinations that support this equilibrium). Ceteris paribus, sales efforts reduce the profits from cooperating on prices by $\mathcal{E}$ every period. Hence, the long-run payoff of cooperation is $\frac{\delta}{1-\delta} f^{r}\left[\frac{k}{m}\left(\frac{\lambda^{c} V}{k}-R\right)-E\right]$ (recall that if all relationship banks spend the same amount in sales effort, they obtain the same number of relationships). On the other hand, at the time that a relationship bank decides to undercut, sales effort expenditures are sunk, like relationship costs $R$. Hence, the gains from undercutting are not affected by sales efforts, and the no-undercutting condition reads

$$
\frac{\delta}{1-\delta} f^{r}\left[\frac{k}{m}\left(\frac{\lambda^{c} V}{k}-R\right)-E\right] \geq \frac{f^{r}}{m}\left[(m-1) \lambda^{c}-(m-k) \alpha\right] V .
$$

This condition is very similar to (4.2) except for term $E$ on the left-hand-side. Call $\mathcal{L}^{E}$ the set of points in the space $\left(\lambda^{c}, m\right)$ such that cooperation is a subgame perfect equilibrium. Then $\frac{\partial \underline{\lambda}^{c}}{\partial E}>0$ and $\frac{\partial \bar{m}}{\partial E}<0$, so that $\mathcal{L}^{E} \subset \mathcal{L}$. Thus:

Proposition 5.2. When nonprice competition by banks increases, fees tend to be higher for a given number of banks $m$. Conversely, the market tends to be more concentrated for a given $\lambda^{c}$.

Proof. See Appendix C. 
The intuition behind Proposition 5.2 should be clear by now: sales efforts, and, more generally, any sunk expenditures, reduce the gains from cooperation but not those of cheating. Hence cooperation must be made more attractive, which is achieved either by increasing concentration or fees. The invariance of the gains of cheating has another implication:

Result 5.3. Relationship banks do not compete away rents with sales efforts.

In many models ex-ante nonprice competition is a mechanism to dissipate ex-post rents. This does not occur here because the incentive to establish relationships relies on rents. Thus, sales efforts do not do away with soft price competition, which is the source of rents in this model.

Result 5.3 has another interesting implication on cross-subsidies among different lines of business. Suppose that one way to attract clients to do "high margin" deals is to sell them other commodity services at fees below cost. This cross subsidization will not dissipate rents in the high margin activities performed by the bank. If that were the case, then relationship banks would want to unilaterally deviate from price norms, thus undermining relationships.

There is a sense, however, in which nonprice competition restrains the market power of banks. As we show now, nonprice competition imposes an upper bound on the fee that investment banks can charge in equilibrium. To see this, note that an additional way for a relationship bank (say, bank 1) to deviate from equilibrium is by escalating sales efforts. In that case bank 1 establishes a relationship with every firm and increases the proportion of firms in its portfolio of relationships, $\eta_{1}$, from $\frac{k}{m}$ to 1 . On the other hand, if bank 1 establishes a relationship with every firm and $E_{2}=E_{m}=E$, there are $k-1$ relationships left for $m-1$ banks for any given firm. $\eta_{i}$ then falls from $\frac{k}{m}$ to $\frac{k-1}{m-1}$ for $i=2,3, \ldots, m$. Thus, if every bank sticks to $\lambda_{i}^{c}=\lambda^{c}$, and then every bank, including bank 1, plays $E_{i}=E$ from $t+1$ on, then bank 1 makes a one-time gain of slightly less than

$$
\begin{aligned}
f^{r}\left[\left(\frac{\lambda^{c} V}{k}-R\right)-E_{1}\right]-f^{r}\left[\frac{k}{m}\left(\frac{\lambda^{c} V}{k}-R\right)-E\right] & \cong f^{r}\left(\frac{\lambda^{c} V}{k}-R\right)\left(1-\frac{k}{m}\right) \\
& =f^{r}\left(\frac{\lambda^{c} V}{k}-R\right) \Delta \eta_{1}>0
\end{aligned}
$$

since relationship bank 1 sets $E_{1}$ a shade above $E$. But, of course, if this is so, then playing $E_{1}=E$ forever cannot be the outcome of an equilibrium, since every bank would have an incentive to unilaterally increase sales efforts every period. It follows that relationship banks will not escalate sales efforts only if that makes undercutting profitable. This is so if (given $m$ ) $\lambda^{c}$ is such that the no-undercutting condition (4.2) does not hold. Since $\eta_{i}, i=2,3, \ldots, m$, falls to $\frac{k-1}{m-1}$ when bank 1 escalates its sales efforts, continued cooperation is not profitable if $\lambda^{c}$ is such that

$$
\frac{\delta}{1-\delta} f^{r}\left[\frac{k}{m}\left(\frac{\lambda^{c} V}{k}-R\right)-E\right]<\frac{f^{r}}{m}\left[(m-\rho) \lambda^{c}-(m-k \rho) \alpha\right] V,
$$


with $\rho \equiv \frac{m}{k} \frac{k-1}{m-1}$.

Figure 7 plots the right and left hand sides of condition (5.2) as a function of $\lambda^{c}$. As can be seen (and some tedious algebra in Appendix C shows), condition (5.2) holds for $\lambda^{c}<\bar{\lambda}^{c}$, with $\bar{\lambda}^{c}$ — derived straightforwardly from condition (5.2) — being equal to

$$
\frac{\frac{\delta}{(1-\delta)} k R-(m-k \rho) \alpha V}{\left[\frac{\delta}{1-\delta}-(m-\rho)\right] V}
$$

(It is straightforward to show that $\bar{\lambda}^{c}>\underline{\lambda}^{c}$; see Appendix C). Thus:

Result 5.4. Competition for establishing relationships sets an upper bound on fees charged by relationship banks.

The intuition behind Result 5.4 is as follows: when $\lambda^{c}$ is too high continued cooperation becomes very attractive and it is not profitable to undercut even if a unilateral deviation in bank's 1 sales reduces everybody's else's market share. But this, of course, cannot occur in equilibrium because then every relationship bank would like to unilaterally increase sales effort. This determines the upper bound on $\lambda^{c}$. Note that the upper bound on $\lambda^{c}$ would be smaller had a unilateral increase in sales effort yielded a smaller increase in the market share of bank 1 , because the gains from undercutting (the left hand side in condition (5.2) would be correspondingly smaller. In this sense, we have truly found an upper bound on $\lambda^{c}$.

\section{Applications}

\subsection{Some antitrust implications}

Ever since the Pujo hearings in the early twentieth century the investment banking market has consistently challenged antitrust authorities. ${ }^{33}$ Fixed and apparently high prices, and the existence of a few dominant banks whose market shares appear not to have changed much in spite of a tenfold growth in market size, concern some observers. Our model can provide some guidance.

Consider first the usual conjecture that soft price competition is an indication of a welfaredecreasing exercise of market power. But, as seen, soft price competition may be necessary to support efficient, relationship-based production technologies. Moreover, nonexcludability implies that this does not result in average cost pricing. Rather, banks must make profits, even after covering their sunk costs of relationships, otherwise the price norm will not be self-enforcing. Thus, excess profits by banks are not sufficient evidence of welfare-decreasing anti-competitive behavior.

\footnotetext{
${ }^{33}$ See Carosso (1970) for a comprehensive account of the Pujo hearings and the antitrust case against the investment banking industry that began in the late 1940s.
} 
A second point is that interventions aimed at increasing competition at the deal (or "local") level may have unintended consequences on fees and aggregate market concentration. Consider, for example, Rule 415 (better known as "shelf registration") ${ }^{34}$ and its effect on increasing the intensity of competition by non-core banks, thus weakening relationships by decreasing the switching cost $\alpha$. Other regulatory interventions may have the aim of increasing the number of banks with whom clients have relationships (an increase in $k$ ). Our model suggests that it is useful to analyze these interventions with an equilibrium logic. First, weakening relationships makes it more difficult to recover the sunk relationship cost $R$. Therefore, the number of firms served by relationship banks should fall. On the other hand, fees or concentration (or both) should increase in the relationship segment of the market, making relationships more attractive to banks. Second, if any of these measures succeed in reducing fees, one should expect a more concentrated market. Thus, looking at changes in concentration as an indication of changes in competitiveness may be misleading.

A third issue that is important in antitrust analysis is the definition of the relevant investment banking market. A common argument is that the large number of small banks in this market imposes some competitive discipline on the pricing behavior of large, bulge-bracket banks. Our analysis suggests that this view may be wrong. Bulge-bracket banks differ from small ones in that they use a relationship-based technology for doing deals. One consequence is that the size of clients served by each segment will be different. Next, differences in bank profits and fees between the two segments will not be eliminated, even with costless entry and exit. Thus, changes in one segment of the market will have no effect on the nature of competition in the other segment other than on the size distribution of clients served by each segment. The point is that, from a firm's perspective, relationship and arm's-length technologies are not substitutes at the margin.

\subsection{Global competition}

Deregulation has allowed many investment banks to set foot in foreign markets, both through acquisitions and foreign subsidiaries. Will global competition, as some observers predict, lead to a unified global investment banking market with only a few megabanks? ${ }^{35}$ Our model suggests that the answer is not straightforward.

Consider, first, changes in regulation that allow or make it easier for foreign banks to enter national markets. Since "global" banks typically specialize in relationships, the logic of the selfenforcing norm that sustains relationships (4.2) applies. This condition implies that there is room

\footnotetext{
${ }^{34}$ Shelf registration was introduced in the early 1980s. It allows firms to eschew the mandatory 20-day waiting period between the registration of the issue with the SEC and the moment the issue can be brought to market. In exchange firms must file a blanket registration document describing their financing plans over the next two years, which is made public. See Auerbach and Hayes (1986) for a thorough analysis.

${ }^{35}$ See, for example, The Economist: "The Doomed and the Dangerous (December 5, 1998), "Investment Banking Boutiques: Small Fried" (June 8, 1996); and "The Last of the Mohicans" (July 20, 1996).
} 
for at most a few relationship banks in each relevant market. If entry by some foreign banks is successful, it necessarily implies that some domestic banks must exit; otherwise the incentives to maintain relationships cannot be preserved. Thus, when foreign banks enter into an established market, one should expect changes in the identities of players, but not substantial consolidation.

A second set of regulatory changes affect firms rather than banks. One such change is to allow firms to list their securities in foreign markets. This enlarges the relevant investment banking market that serves large firms from the national to the international level (e.g. one common European market, or Asian and Latin American firms floating their securities in New York). For investment banks, this increases the size of the market. An implication of Result 4.9 is that market structure is independent of market size. It follows that liberalization of listing requirements should lead to massive consolidation of relationship banks at the global level.

A third implication of the model is that neither liberalization of bank entry into national markets nor of listing requirements for firms in foreign markets should change the dual market structure of investment banking within each country. The reason is that fringe banks specialize in serving small firms which generate too little volume to justify establishing relationships and global banks tend to specialize in relationships. Hence, small firms and fringe banks should not be affected much by what happens in the relationship segment, at which most regulatory changes are aimed.

Last, consider how these trends are likely to affect emerging markets. Liberalizing entry of foreign investment banks is sometimes thought to be a means of jump-starting investment banking, which should lower the cost of funds for local firms. However, even "medium sized" and "large" firms by the standards of emerging markets tend to be "small" when compared with the firms usually served by global banks. The model suggests that the size of the market, as measured by the number of firms that potentially demand investment banking services, is not a very relevant determinant of a global bank's decision of entry. What matters is the size distribution of firms. A "large" market where there are many firms but few of them are large, may be considerably less attractive than a small market with several large corporations. The reason is that the fundamental sunk cost- $R$-is incurred at the firm, not the market level.

\subsection{Can relationships survive the Internet?}

The Internet appears to have important consequences for the relationships between investment banks and firms. ${ }^{36}$ It can reduce the costs of any bank - relationship or fringe - in accessing infor-

\footnotetext{
${ }^{36}$ We do not discuss the effect of the Internet on relationships between banks and investors, and how this affects their function of distributing and marketing issuers' securities. Wilhelm (1999) provides a comprehensive analysis of this, and discusses the role of new intermediaries like Wit Capital and OffRoad Capital, as well as Internet forays by incumbents like Goldman Sachs.
} 
mation on a company, ${ }^{37}$ and, as some observers have suggested, it may also increase the ability to codify and analyze vast amounts of information that previously relied on human judgement and experience. ${ }^{38}$ Both effects work to increase the substitutability of relationship and non-relationship technologies, thus reducing $\beta$.

The Internet should also reduce the costs of communication between firms and banks, thus reducing $R$. And, for the same reason, this should allow firms to increase the number of banks with which they interact, thus increasing $k$.

Making relationships less costly and exclusive, and easier to substitute by arm's-length transactions might be thought to increase competition. But in fact they can have opposite effects. Clearly, lower costs of establishing relationships (lower $R$ ) tend to reduce fees and concentration. On the other hand, increasing $k$ de facto reduces the revenues from any relationship. Concentration (or fees) must then increase to preserve the incentives to establish relationships. At the same time, changes in $\beta$ do not affect the sustainability of relationships as long as they are not very large.

\section{Concluding remarks}

Investment banking relationships are idiosyncratic in some ways. The loose linkage between costs and fees, and the fact that much of the information gathered via relationships is not excludable, may not characterize relationships in other banking markets. Moreover, unlike commercial banks, investment banks do not hold firm's securities on a long-term basis; they underwrite, rather than lend (although these distinctions may be disappearing). Therefore, some of the results in this paper need not carry over to other banking markets. On the other hand, in any intermediation market relationships are made possible by some variation of imperfect competition. Understanding where market structure comes from in each case is useful to analyze the consequences of changes in competitive conditions and regulations. This is the more general message of the paper.

\footnotetext{
${ }^{37}$ An important distinguishing feature of the Net from previous information technologies in this regard is its use of hub-and-spoke network technologies as opposed to point-to-point networks.

${ }^{38}$ See, for example, Wilhelm and Downing's (2000) account of OffRoad Capital.
} 


\section{Appendix}

\section{A. A subgame perfect equilibrium with no undercutting}

In this appendix we construct a strategy combination that is a subgame perfect equilibrium whose outcome are the conditions examined in the text. We start by defining a strategy combination that is a subgame perfect equilibrium of the one-period game.

Definition A.1. Call strategy combination $P$ (for 'punishment') the following combination of strategies

- For all relationship banks $i$

1. $\mathcal{R}_{i}(v)=0$ for all $v \in[0, \bar{v}]$;

2 .

$$
\left(\lambda_{i}^{c}, \lambda_{i}^{n c}, \lambda_{i}^{n r}\right)= \begin{cases}(0,0,0) & \text { if } i \text { is member of at least one core group and not member } \\ & \text { of at least another core group; } \\ (\infty, 0,0) & \text { if } i \text { is member of no core group but at least one exists; } \\ (\infty, \infty, 0) & \text { if no core groups are established. }\end{cases}
$$

- For all fringe banks $j, \lambda_{j}^{f}=0$.

Part (i) of the strategy of relationship banks implies that no bank establishes a relationship. Part (ii) implies that $i$ undercuts other relationship banks on all histories such that $i$ is in a core group. Finally, part (iii) implies that bank $i$ always undercuts when not in a core group. We are now ready to prove the following lemma:

Lemma A.2. Strategy combination $P$ is a subgame perfect equilibrium of the one period game.

Proof. Consider first histories where at least one firm establishes relationships with $k$ banks and forms its core group. According to $P$, for these histories we have to distinguish three cases:

$$
\left(\lambda_{i}^{c}, \lambda_{i}^{n c}, \lambda_{i}^{n r}\right)= \begin{cases}(0, \infty, 0) & \text { if bank } i \text { is member of all core groups; } \\ (0,0,0) & \text { if there is at least one core group where bank } i \text { is not a member } \\ & \text { but bank } i \text { is member of at least one core group; } \\ (\infty, 0,0) & \text { if bank } i \text { is member of no core group. }\end{cases}
$$

In any of these three cases, any unilateral deviation by bank $i$ setting $\lambda_{i}^{c}>0$ or $\lambda_{i}^{n c}>0$ or $\lambda_{i}^{n r}>0$ as the case may be will not increase its payoff, since it would get no deals.

Consider next histories where no firm forms a core group. Then, $\left(\lambda_{i}^{c}, \lambda_{i}^{n c}, \lambda_{i}^{n r}\right)=(\infty, \infty, 0)$ according to $P$. Setting $\lambda_{i}^{n r}>0$ will not increase $i$ 's payoff since it would get no deals.

Last, setting $\mathcal{R}_{i}(v)=R$ for one or more $v$ 's will not increase $i$ 's payoff because according to strategies no other firm establishes relationships.

The following corollary follows from Proposition 3.1 and Lemma A.2.

Corollary A.3. All banks receive a payoff equal to 0 in the one period game.

Thus, since playing strategy combination $P$ forever is clearly a subgame perfect equilibrium in the infinitely repeated game, it follows that it can be used to construct a subgame perfect punishment. We now specify a strategy combination such that cooperation is a subgame perfect equilibrium. To do so, it is useful to assign each possible history of the game into one of two disjoint sets.

Definition A.4. We say that the history of the game at period $t$ is 'cooperative' if and only if no undercutting has occurred so far. That is, for all $\tau<t, \min \left\{\lambda_{i}^{c}(\tau), \lambda_{i}^{n c}(\tau)+\alpha\right\} \geq \lambda^{c}$. Any other history is non-cooperative. 
Notation A.5. We denote the state of the game at period $t$ by $\phi_{t}$. The state of the game after a history with no undercutting is cooperative and is denoted by $\phi^{c}$. Any other state of the game is 'non-cooperative' and is denoted by $\phi^{n c}$.

Note that this definition implies that the initial state of the game is cooperative. Next we define some notation we need to define strategies:

Notation A.6. As in the text, $\eta_{i}$ denotes the share of firms with $v \geq \underline{v}$ such that bank $i$ is in their core group. Furthermore, we denote by $\eta_{-i}$ the fraction of firms with $v \geq \underline{v}$ that have a core group where relationship bank $i$ is not a member

Note that that $1-\eta_{i}-\eta_{-i}$ is the fraction of firms with $v \geq \underline{v}$ who did not form a core group. Hence, if all firms formed a core group then $\eta_{-i}=1-\eta_{i}$. Furthermore, $1-\eta_{i}-\eta_{-i}=1-\eta_{j}-\eta_{-j}$ for all $i, j$. We can now define the symmetric strategy combination $C$ (for 'cooperative').

Definition A.7. Call strategy combination $C$ the following combination of strategies:

- For all relationship banks $i$

1. (Establishing relationships)

- If $\phi_{t}=\phi^{c}$ then play

$$
\mathcal{R}_{i}(v)=\left\{\begin{array}{l}
R \text { for } v \geq \underline{v}, \\
0 \text { for } v<\underline{v} .
\end{array}\right.
$$

- Otherwise, play according to $P$.

2. (Fee offers)

- If $\phi_{t}=\phi^{c}$ and

$$
\frac{\delta}{1-\delta} f^{r} \frac{k}{m}\left(\frac{\lambda^{c} V}{k}-R\right) \geq \max _{j}\left\{f^{r}\left[\eta_{j}\left(1-\frac{1}{k}\right) \lambda^{c}+\eta_{-j}\left(\lambda^{c}-\alpha\right)\right] V\right\}
$$

holds, then play

$$
\left(\lambda_{i}^{c}, \lambda_{i}^{n c}, \lambda_{i}^{n r}\right)= \begin{cases}\left(\lambda^{c}, \infty, 0\right) & \text { if } \eta_{i}>0 \\ (\infty, \infty, 0) . & \text { if } \eta_{i}=0 .\end{cases}
$$

- Otherwise play according to $P$.

- For all fringe banks $j$ play $\lambda_{j}^{f}=0$.

Condition (A.1) says that bank $i$ will not undercut in period $t$ provided that continued cooperation is more profitable than undecutting, given period's $t$ ex ante fee offers. Lemma A.8 characterizes the outcome path induced by $C$ :

Lemma A.8. Along the path induced by $C$

(i) all relationship banks $i$ play $\left(\lambda_{i}^{c}, \lambda_{i}^{n c}, \lambda_{i}^{n r}\right)=\left(\lambda^{c}, \infty, 0\right)$ for all $t$;

(ii) all relationship banks have the same market share;

(iii) all fringe banks play $\lambda_{j}^{f}=0$ for all $t$.

Proof. The proof is straightforward and we leave it to the reader.

We now state and prove the main result of this appendix:

Proposition A.9. Let $\left(\lambda^{c}, m\right) \in \mathcal{L}$. Then, strategy combination $C$ is a subgame perfect equilibrium in the infinitely repeated game. 
Proof. To prove this Proposition, we show that players' strategies are optimal after any history. Since this is a repeated game with bounded payoffs, it suffices to show that one-step unilateral deviations from strategies are not profitable after any history.

Now according to $C$ histories can be classified into two groups, cooperative and non cooperative. Consider, then, histories after which the state of the game is non-cooperative $\left(\phi_{t}=\phi^{n c}\right)$. We know that when all other relationship banks are playing according to $P$ in the one-period game, it is optimal for bank $i$ to do the same. Since all realtionship banks will play according to $P$ forever after, it is also optimal for relationship bank $i$ to play according to $P$ in any period of the repeated game.

Next consider histories after which the state of the game is cooperative $\left(\phi_{t}=\phi^{c}\right)$, relationship banks must make fee offers and condition (A.1) does not hold. Then all relationship banks play according to $P$, from which we know it is optimal not to deviate.

Now consider histories after which the state of the game is cooperative $\left(\phi_{t}=\phi^{c}\right)$, relationship banks must make fee offers, $\eta_{i}>0$ and condition (A.1) holds. Then bank $i$ can not gain by undercutting (as condition [A.1] implies). On the other hand, if bank $i$ would set $\lambda_{i}^{c}>\lambda^{c}$ or $\lambda_{i}^{n c} \in\left(\lambda_{1}^{a}+\alpha, \infty\right)$ it would not get any further deals; and setting $\lambda_{i}^{n r}>0$ would not get any further deals either. Thus, playing $\left(\lambda_{i}^{c}, \lambda_{i}^{n c}, \lambda_{i}^{n r}\right)=\left(\lambda^{c}, \infty, 0\right)$ is optimal. Moreover, if $\eta_{i}=0$ but $\eta_{-i}>0$ it would not gain deviating from setting $\left(\lambda_{i}^{c}, \lambda_{i}^{n c}, \lambda_{i}^{n r}\right)=(\infty, \infty, 0)$. Last, if $\eta_{i}=\eta_{-i}=0$ relationship bank $i$ cannot gain by undercutting.

Next consider histories after which the state of the game is cooperative $\left(\phi=\phi^{c}\right)$ and banks must decide whether to establish relationships. Clearly a relationship bank cannot gain by deviating and $\operatorname{setting} \mathcal{R}(v)=0$ for firms such that $v \geq \underline{v}$ (it would lose $\left(\frac{\lambda^{c} V}{k}-R\right.$ ) per firm in the current period according to strategies) or by sinking the relationship cost with a firm such that $v<\underline{v}$ (since such a firm will not be successful in establishing a core group according to strategies because $\left.\left(\frac{\lambda^{c} v}{k}-R\right)<0\right)$. Hence setting $\mathcal{R}(v)=R$ for $v \geq \underline{v}$ and $\mathcal{R}(v)=0$ for $v<\underline{v}$ is optimal.

Last, note that playing $\lambda_{j}^{f}=0$ is optimal for fringe banks in the one-period game, hence it is also optimal to play so in the repeated game. This completes the proof.

\section{B. Comparative equilibria}

In this appendix we obtain the comparative equilibria derivatives that are presented in the text. All are obtained by totally differentiating the identity

$$
\frac{\delta}{1-\delta} k\left(\frac{\lambda^{c} V}{k}-R\right)-\left[(m-1) \lambda^{c}-(m-k) \alpha\right] V \equiv 0
$$

which is derived from the no undercutting condition (4.2). Totally differentiating this identity with respect to $\lambda^{c}, m$, $k$ and $\alpha$, recalling that $\varepsilon_{V, \lambda} \equiv-\frac{\partial V}{\partial \lambda^{c}} \frac{\lambda^{c}}{V}$, and simplifying yields

$$
\begin{aligned}
& \left\{\left[\frac{\delta}{1-\delta}-(m-1)\right]\left(1-\varepsilon_{V, \lambda^{c}}\right)-\frac{\alpha}{\lambda^{c}}(m-k) \varepsilon_{V, \lambda^{c}}\right\} V \mathrm{~d} \lambda^{c}-\left(\lambda^{c}-\alpha\right) V \mathrm{~d} m \\
& -\left\{\left[(m-1) \lambda^{c}-(m-k)\right] \frac{\partial V}{\partial k}+\alpha V-\frac{\delta}{1-\delta}\left(\lambda^{c} \frac{\partial V}{\partial k}-R\right)\right\} \mathrm{d} k+(m-k) V \mathrm{~d} \alpha \equiv 0,
\end{aligned}
$$

which can be rewritten as

$$
A \mathrm{~d} \lambda^{c}-B \mathrm{~d} m-C \mathrm{~d} k+D \mathrm{~d} \alpha \equiv 0
$$

It will be useful to sign the coefficients in identity (B.1). Clearly $B>0$ (since $\lambda^{c}>\alpha$ ) and $D>0$ (since $m>k$ ). To sign $C$ note first that $(m-1) \lambda^{c}-(m-k)=k-\lambda^{c}>0$. Moreover, since $\frac{\partial V}{\partial k}=\frac{R}{2 \lambda^{c}}=\frac{\underline{v}}{2 k}>0$ it follows that

$$
\lambda^{c} \frac{\partial V}{\partial k}-R=\lambda^{c} \frac{\underline{v}}{2 k}-R<0
$$

since $\lambda^{c} \frac{\underline{v}}{\bar{k}}-R=0$ by the definition of $\underline{v}$. It follows that $C>0$. Finally, noting that $\varepsilon_{V, \lambda^{c}}=\frac{\underline{v}}{\bar{v}+\underline{v}}$, $A$ an be rewritten as

$$
\frac{1}{\bar{v}+\underline{v}}\left\{\left[\frac{\delta}{1-\delta}-(m-1)\right] \bar{v}-\frac{\alpha}{\lambda^{c}}(m-k) \underline{v}\right\}
$$

whose sign is ambiguous but positive if $\alpha$ is sufficiently small. Now if $A>0$ then the following result follows.

Proposition B.1. If $A>0$ then: 


$$
\begin{aligned}
& \frac{\mathrm{d} m}{\mathrm{~d} \underline{\lambda}^{c}}=\frac{A}{B}>0 ; \\
& \frac{\mathrm{d} \underline{\lambda}^{c}}{\mathrm{~d} k}=\frac{C}{A}>0 ; \\
& \frac{\mathrm{d} \underline{\lambda}^{c}}{\mathrm{~d} \alpha}=-\frac{D}{A}<0 ; \\
& \frac{\mathrm{d} \bar{m}}{\mathrm{~d} k}=-\frac{C}{B}<0 ; \\
& \frac{\mathrm{d} \bar{m}}{\mathrm{~d} \alpha}=\frac{D}{B}>0 .
\end{aligned}
$$

Proof. By direct substitution.

\section{Nonprice competition}

To analyze nonprice competition we replace the first stage of the one period game. As mentioned in the text, instead of firms randomly choosing $k$ relationship banks, we have relationship banks choosing sales effort $E_{i}$.

It is easy to show that in the one-period game relationship banks will not spend anything in sales efforts and that no relationships will be established. Thus, as before, the equilibrium in the one period game can be used as a subgame perfect punishment. Call again this subgame perfect punishment $P$. Next define 'undercutting' and 'cooperative' and 'non-cooperative' states exactly as in the previous section. ${ }^{39}$ Last, we need one piece of additional notation to keep track of the fraction of firms that contact relationship bank $i$ inresponse of $i$ 's sales effort:

Notation C.1. We denote by $\gamma_{i}$ the fraction of firms with $v \geq \underline{v}$ that contact relationship bank $i$ after $i$ has chosen $E_{i}$.

Recall that, by definition, $E_{1} \geq E_{2} \geq \ldots \geq E_{m}$. Hence, our assumptions imply that $\gamma_{i}$ is a function $\gamma_{i}: \mathrm{R}_{+}^{m} \rightarrow$ $[0,1]$ such that

$$
\gamma_{i}\left(E_{1}, \ldots, E_{i}, \ldots, E_{m}\right)= \begin{cases}0 & \text { if } E_{i}<\underline{E} \text { or } E_{i}<E_{k} \\ \frac{1}{y} & \text { if } E_{i}=E_{k} \geq \underline{E} \text { and } y \text { banks make the } k \text { th largest sales effort; } \\ \frac{1}{m} & \text { if } E_{1}=E_{m} \geq \underline{E} \\ 1 & \text { if } E_{i}>E_{k} \text { and } E_{i} \geq \underline{E} .\end{cases}
$$

Function $\gamma_{i}$ summarizes how banks sales efforts bring about contacts with firms. Note that $\sum_{i=1}^{m} \gamma_{i}=k$ if $E_{k} \geq \underline{E}$. We can now define a strategy combination that is a subgame perfect equilibrium in the game with sales effort.

Definition C.2. Call strategy combination $C$ the following combination of strategies:

- For all relationship banks $i$

1. 1. (Sales effort)

- If $\phi_{t}=\phi^{c}$ then play $E_{i}=E \geq \underline{E}$;

- Otherwise, play $E_{i}=0$.

2. (Establishing relationships)

\footnotetext{
${ }^{39}$ Note that this implies that the state of the game is determined only by the pricing behavior of relationship banks, and not by their sales efforts.
} 
- If $\phi_{t}=\phi^{c}$ and and

$$
\frac{\delta}{1-\delta} f^{r}\left[\frac{k}{m}\left(\frac{\lambda^{c} V}{k}-R\right)-E\right] \geq \max _{j}\left\{f^{r}\left[\gamma_{j}\left(1-\frac{1}{k}\right) \lambda^{c}+\left(1-\gamma_{j}\right)\left(\lambda^{c}-\alpha\right)\right] V\right\}
$$

then play

$$
\mathcal{R}_{i}(v)=\left\{\begin{array}{l}
R \text { for } v \geq \underline{v}, \\
0 \text { for } v<\underline{v} .
\end{array}\right.
$$

- Otherwise, play $\mathcal{R}_{i}(v)=0$ for all $v \in[\underline{v}, \bar{v}]$

3. (Fee offers)

- If $\phi_{t}=\phi^{c}$ and

$$
\frac{\delta}{1-\delta} f^{r}\left[\frac{k}{m}\left(\frac{\lambda^{c} V}{k}-R\right)-E\right] \geq \max _{j}\left\{f^{r}\left[\eta_{j}\left(1-\frac{1}{k}\right) \lambda^{c}+\eta_{-j}\left(\lambda^{c}-\alpha\right)\right] V\right\}
$$

then play

$$
\left(\lambda_{i}^{c}, \lambda_{i}^{n c}, \lambda_{i}^{n r}\right)= \begin{cases}\left(\lambda^{c}, \infty, 0\right) & \text { if } \eta_{i}>0 \\ (\infty, \infty, 0) & \text { if } \eta_{i}=0 .\end{cases}
$$

- Otherwise play according to $P$.

- For all fringe banks $j$ play $\lambda_{j}^{f}=0$.

Like in the previous section, condition (C.3) says that bank $i$ will not undercut in period $t$ provided that continued cooperation is more profitable than undecutting. Note that this no-undercutting condition is exactly the same as condition (A.1) in the previous section, except for the fact that sales effort expenditures $E$ are included in the left-hand side of condition (C.3). Lemma A.8 characterizes the outcome path induced by $C$.

Lemma C.3. Along the path induced by $C$

(i) all relationship banks $i$ select $E_{i}=E$;

(ii) all relationship banks $i$ play $\left(\lambda_{i}^{c}, \lambda_{i}^{n c}, \lambda_{i}^{n r}\right)=\left(\lambda^{c}, \infty, 0\right)$ for all $t$;

(iii) all relationship banks have the same market share;

(iv) all fringe banks play $\lambda_{j}^{f}=0$ for all $t$.

Proof. The proof is straightforward and we leave it to the reader.

We now state and prove the main result of this section:

Proposition C.4. Let $\left(\lambda^{c}, m\right) \in \mathcal{L}^{E}$. Then strategy combination $C$ is a subgame perfect equilibrium in the infinitely repeated game with sales effort. Moreover,

$$
\underline{\lambda}^{c} \leq \lambda^{c}<\bar{\lambda}^{c}=\frac{\frac{\delta}{1-\delta}\left(\frac{k}{m} R+E\right)-\frac{1}{m}(m-k \rho) \alpha V}{\frac{V}{m}\left[\frac{\delta}{1-\delta}-(m-\rho)\right]},
$$

with $\rho \equiv \frac{m}{k} \frac{k-1}{m-1}$.

Proof. To prove this proposition, we show that the players' strategies for the repeated game are optimal after any history. Again, since this is a repeated game with bounded payoffs, it suffices to show that one-step unilateral deviations from strategies are not profitable after any history.

Now as before, according to $C$ histories can be classified in two groups, cooperative and non-cooperative. Consider, then, histories after which the state of the game is non-cooperative $\left(\phi_{t}=\phi^{n c}\right)$. We know that when all other banks are playing according to $P$ in the one-period game, it is optimal for bank $i$ to do the same. Since all banks will play according to $P$ forever after, it is also optimal for bank $i$ to play according to $P$ in any period of the repeated game.

Now consider histories after which the state of the game is cooperative $\left(\phi_{t}=\phi^{c}\right)$ and relationship banks must make fee offers. Then, with the exception of the sales effort $E$ on the left-hand side of (C.3), the continuation 
game's strategies look exactly as in the game without sales effort. Hence, one-shot deviations from strategies are unprofitable.

Next consider histories after which the state of the game is coperative and relationship banks must decide whether to establish relationships with firms. If condition (C.3) holds, and all relationship banks conform to strategies, then $\gamma_{j}=\eta_{j}$ (that is, all relationship banks establish relationships with all firms they contacted) and $1-\gamma_{j}=\eta_{-j}$ for all $j$. Hence condition (C.3) also holds and cooperation continues. A unilateral deviation by relationaship bank $i$ not establishing relationships is therefore unprofitable (see the proof of Proposition A.9). On the other hand, if condition (C.2) does not hold, then no relationship bank establishes relationships, and so it is optimal for $i$ not to establish them either.

Next consider sales effort decisions when the state of the game is cooperative. According to strategies all relationship banks play $E_{j}=E$. Hence, a unilateral deviation is to play $E_{1} \neq E$. If $E_{1}>E$ then $E_{1}>E_{2}=\ldots=E_{m}$. It follows from (C.1) that $\gamma_{1}=1$ and $\gamma_{2}=\ldots=\gamma_{m}=\frac{k-1}{m-1}$. Such unilateral deviation is unprofitable if

$$
\frac{\delta}{1-\delta} f^{r}\left[\frac{k}{m}\left(\frac{\lambda^{c} V}{k}-R\right)-E\right]<\frac{f^{r}}{m}\left[(m-\rho) \lambda^{c}-(m-k \rho) \alpha\right] V
$$

otherwise it would pay to deviate to increase market share for one time. Now some straightforward algebra shows that condition (C.4) holds if and only if $\lambda^{c}<\bar{\lambda}^{c}$.

Last, consider playing $E_{m}<E$. Then $\gamma_{m}=0$ and clearly condition (C.3) does not hold, since it holds with equality with $\lambda^{c}=\bar{\lambda}^{c}$ and $\min _{j} \gamma_{j}=\frac{k-1}{m-1}$. Hence, if relationship bank $m$ deviates selecting $E_{m}<E$, then no relationships are established in that period and profits are foregone. This completes the proof.

\section{Proof of Result 5.2}

To prove this result, let condition (5.1) hold as an identity and then totally differentiate with respect to $\lambda^{c}, m$ and $E$. This yields

$$
A \mathrm{~d} \lambda^{c}-\left(\lambda^{c}-\alpha+\frac{\delta}{1-\delta} E\right) \mathrm{d} m-\frac{\delta}{1-\delta} m \mathrm{~d} E=0
$$

where $A$ is defined as in Appendix B. Setting $\mathrm{d} m=0$, straightforward manipulations yield

$$
\frac{\mathrm{d} \lambda^{c}}{\mathrm{~d} E}=\frac{\delta}{1-\delta} \frac{m}{A}>0
$$

Similarly, setting $\mathrm{d} \lambda^{c}=0$ and rearranging yields

$$
\frac{\mathrm{d} m}{\mathrm{~d} E}=-\frac{\delta}{1-\delta} \frac{m}{\lambda^{c}-\alpha+\frac{\delta}{1-\delta}}<0 .
$$

This completes the proof.

\section{References}

[1] Allen, F. and D. Gale, Comparing Financial Systems. Cambridge: MIT Press, 2000.

[2] Anand, B. and A. Galetovic, "Information, Non-excludability and Financial Market Structure", Journal of Business 73, 357-402, 2000.

[3] Aoki, M. and S. Dinc, "Relational Financing as an Institutiona and its Viability under Competition," CEPR publication $\mathrm{N}^{\circ} 488,1997$.

[4] Auerbach, J. and S. Hayes, Investment Banking and Diligence: What Price Deregulation. Boston: Harvard Business School Press, 1986.

[5] Baker, W., "Market Networks and Corporate Behavior," American Journal of Sociology 96, 589-625, 1990.

[6] Bloch, E., Inside Investment Banking (2nd ed.). New York: Irvin, 1989.

[7] Carosso, V., Investment Banking in America. Cambridge: Harvard University Press, 1970.

[8] Chen, H. and J. Ritter, "The Seven Percent Solution," Journal of Finance 55, 1105-1131, 2000. 
[9] Detragiache, E., P. Garella and L. Guiso, "Multiple versus Single Banking Relationships: Theory and Evidence," Journal of Finance 55, 1133-1161, 2000.

[10] Dutta, P. and A. Madhavan, "Competition and Collusion in Dealer Markets," Journal of Finance 52, 245-276, 1997.

[11] Eccles, R. and R, Crane, Doing Deals: Investment Banks at Work. Boston, Harvard Business School Press, 1988.

[12] Elsas, R. and J. Krahnen, "Is Relationship Lending Special? Evidence from Credit-file Data in Germany", Journal of Banking and Finance 22, 1283-1316, 1998.

[13] Fudenberg, D. and E. Maskin, "The Folk Theorem in Repeated Games with Discounting or with Incomplete Information." Econometrica 54, 533-54, 1986.

[14] Harris, M. and B. Holmstrom, "A Theory of Wage Dynamics," Review of Economic Studies 49, 315-333, 1982.

[15] Hayes, S., and Hubbard, Investment Banking: A Tale of Three Cities. Boston: Harvard Business School Press, 1990.

[16] Hayes, S., and A. Regan, "Securities Underwriting and Investment Banking Competition," in S. Hayes (ed.), Financial Services: Perspectives and Challenges, Boston: Harvard Business School Press, 1993.

[17] Hayes S., M. Spence and D. Marks, Competition in the Investment Banking Industry. Cambridge: Harvard University Press, 1983.

[18] Hellmann, T., Murdoch and J. Stiglitz, "Financial Restraint: Towards a New Paradigm," in M. Aoki, M.Kim and H. Okuno-Fujiwara (eds.) The Role of Government in East Asian Economic Development. New York: Oxford University Press, 1997.

[19] Hellwig, M., "Banking, Financial Intermediation and Corporate Finance," in A. Giovannini and C. Mayer (eds.), European Financial Inegration. New York: Cambridge University Press, 1991.

[20] James, C., "Some Evidence on the Uniqueness of Bank Loans," Journal of Financial Economics 19, 217-235, 1987.

[21] James, C., "Relationship-Specific Assets and the Pricing of Underwriter Services," Journal of Finance 47, 1865-1885, 1992.

[22] Kang, J., A. Shivdasani and T. Yamada, "The Effect of Bank Relations on Investment Decisions: An Investigation of Japanese Takeover Bids", Journal of Finance 55, 2197-2218, 2000.

[23] Lummer, S. and J. McConnel, "Further Evidence on the Bank Lending Process and the Capital Market Response to Bank Loan Agreements," Journal of Financial Economics 25, 99-122, 1989.

[24] Mayer, C., "New Issues in Corporate Finance", European Economic Review 32, 1167-1189, 1988.

[25] Mas-Collell, A. M. Whinston and J. Green, Microeconomic Theory. New York: Oxford University Press, 1995

[26] Matthews, J., Struggle and Survival on Wall Street. New York: Oxford University Press, 1994.

[27] Petersen, M., and R. Rajan, "The Benefits of Lending Relationships: Evidence from Small Business Data," Journal of Finance 49, 3-37, 1994.

[28] Petersen, M., and R. Rajan, "The Effect of Credit Market Competition on Lending Relationship," Quarterly Journal of Economics 110, 407-443, 1995.

[29] Rajan, R., "Insiders and Outsiders: The Choice between Informed and Arm's-Length Debt," Journal of Finance 47, 1367-1400, 1992.

[30] Rajan, R., "The Entry of Commercial Banks into the Securities Business: A Selective Survey of Theories and Evidence," mimeo, University of Chicago, Graduate School of Business, 1995.

[31] Rolfe, J. and P. Troob, Monkey Business: Swinging Through the Wall Street Jungle. New York: Warner Books, 2000 .

[32] Rosen, H. Public Finance (3rd ed.). Boston: Irwin, 1992.

[33] Shockley, R. and A. Thakor, "Bank Loan Commitments: Data, Theory and Tests," Journal of Money, Credit and Banking 29, 517-534, 1997.

[34] Smith, C., "Investment Banking and the Capital Acquisition Process," Journal of Financial Economics 15, 3-29, 1986. 
[35] Sutton, J., Sunk Costs and Market Structure: Price Competition, Advertising, and the Evolution of Concentration. Cambridge: MIT Press, 1991

[36] Sutton, J., "Game-Theoretic Models of Market Structure." In D. Kreps and K. Wallis (eds.) Advances in Economics and Econometrics: Theory and Applications. New York: Cambridge University Press, 1997.

[37] Tufano, P., "Financial Innovation and First-Mover Advantages," Journal of Financial Economics 25, 213-240, 1989.

[38] Wilhelm, W., "Internet Investment Banking: The Impact of Information Technology on Relationship Banking," Journal of Applied Corporate Finance 12, Spring 1999.

[39] Wilhelm, W. and J. Downing, The Information Technology Revolution in Financial Markets, forthcoming.

[40] Williamson, O., "Transaction Cost Economics: The Governance of Contractual Relations," Journal of Law and Economics 22, 233-261, 1979.

[41] Yasuda, A., "Relationship Capital and Competition in the Corporate Securities Undewriting Market," mimeo, 1999. 


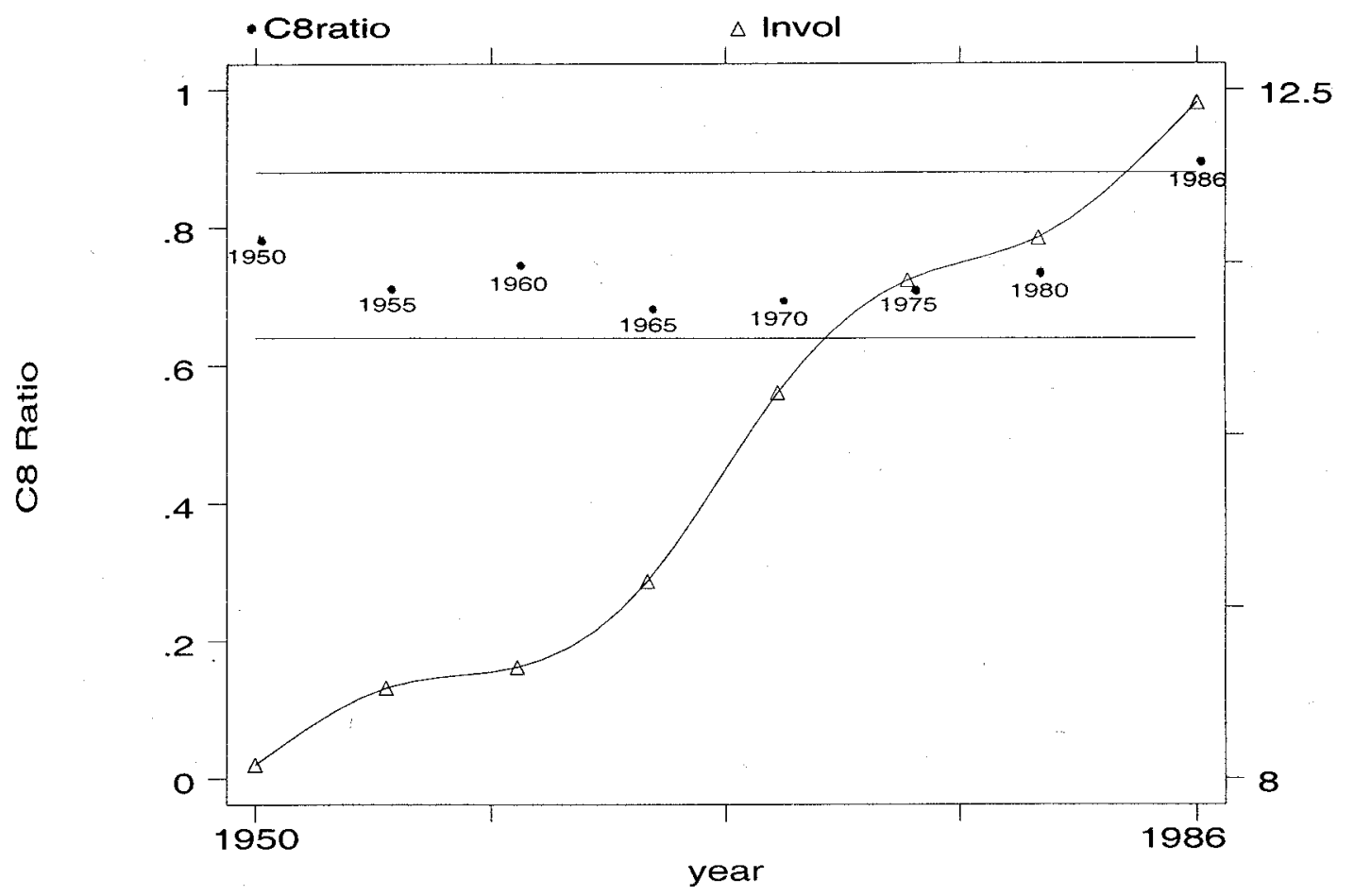

0
0
0
$\vdots$
0
0
$\frac{0}{2}$
0
$>$

Figure 1. Concentration and Volume in Underwriting

Source: Hayes, Spence, and Marks (1983), table 1, and Eccles and Crane (1988), table 5.4.

"C8-Ratio" is the share of total volume of securities underwritten in any given year by the top eight investment banks. Full credit is given to lead manager. "Volume" is the logarithm of total volume of securities underwritten in any given year. 


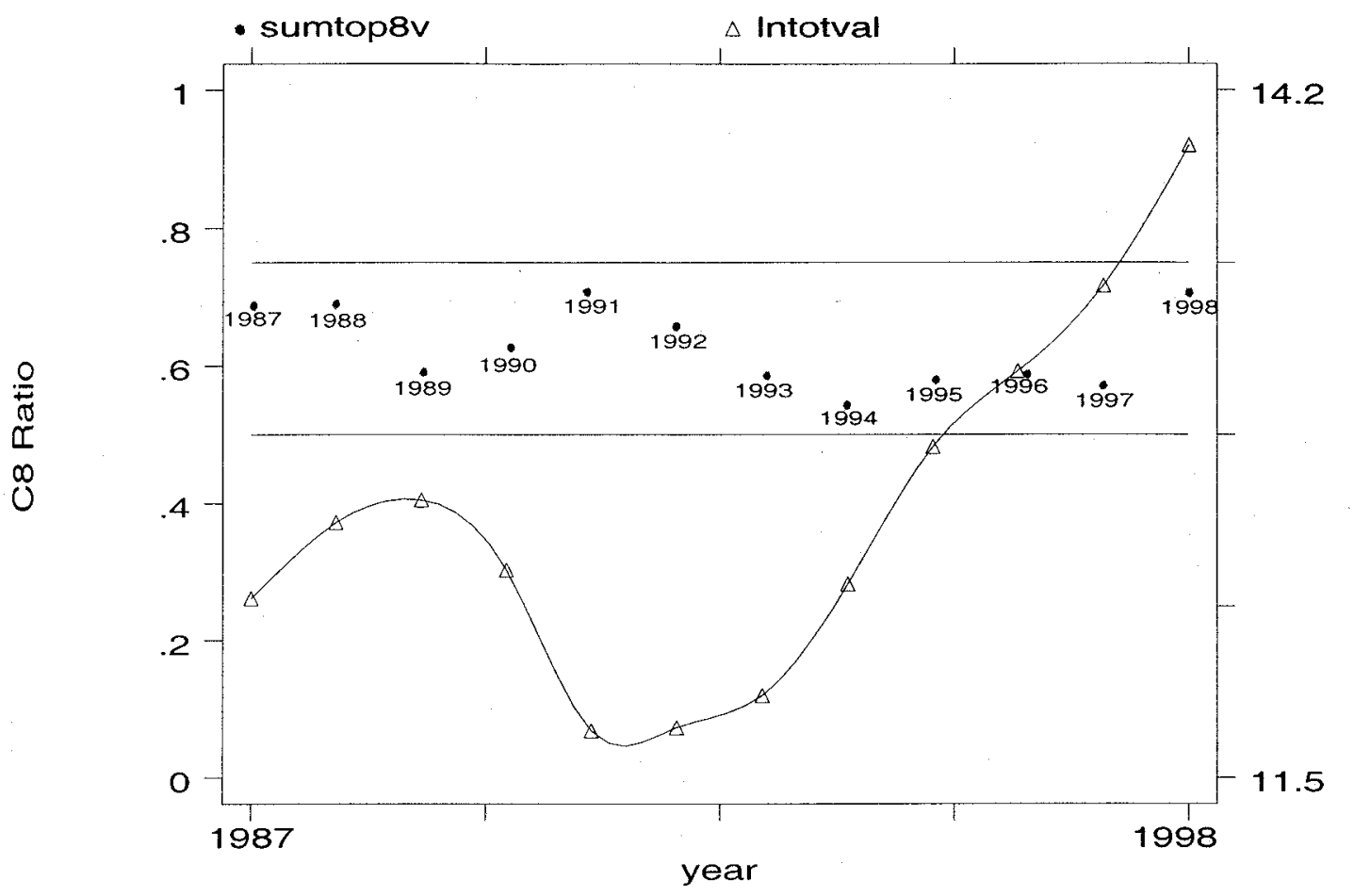

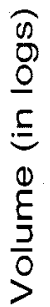

Figure 2. Concentration and Volume in Mergers and Acquisitions Source: Author's processing of data from Securities Data Company. "C8-Ratio" is the share of total deal value of mergers and acquisitions brokered by the top eight investment banks in any given year. Full credit is given to the acquiror's lead bank. The sample of M\&A deals is restricted to those made by firms that do at least three such deals in the 12-year period 1987-1998. 


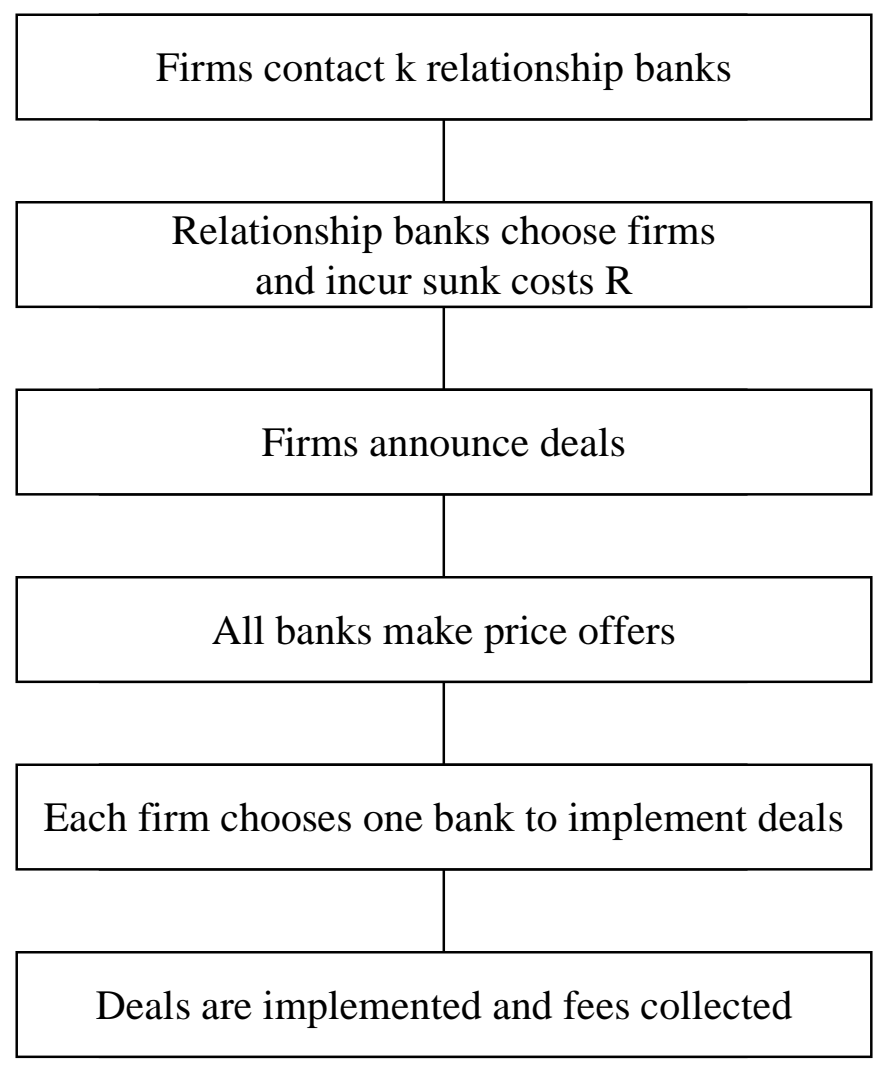

Figure 3. Timeline 


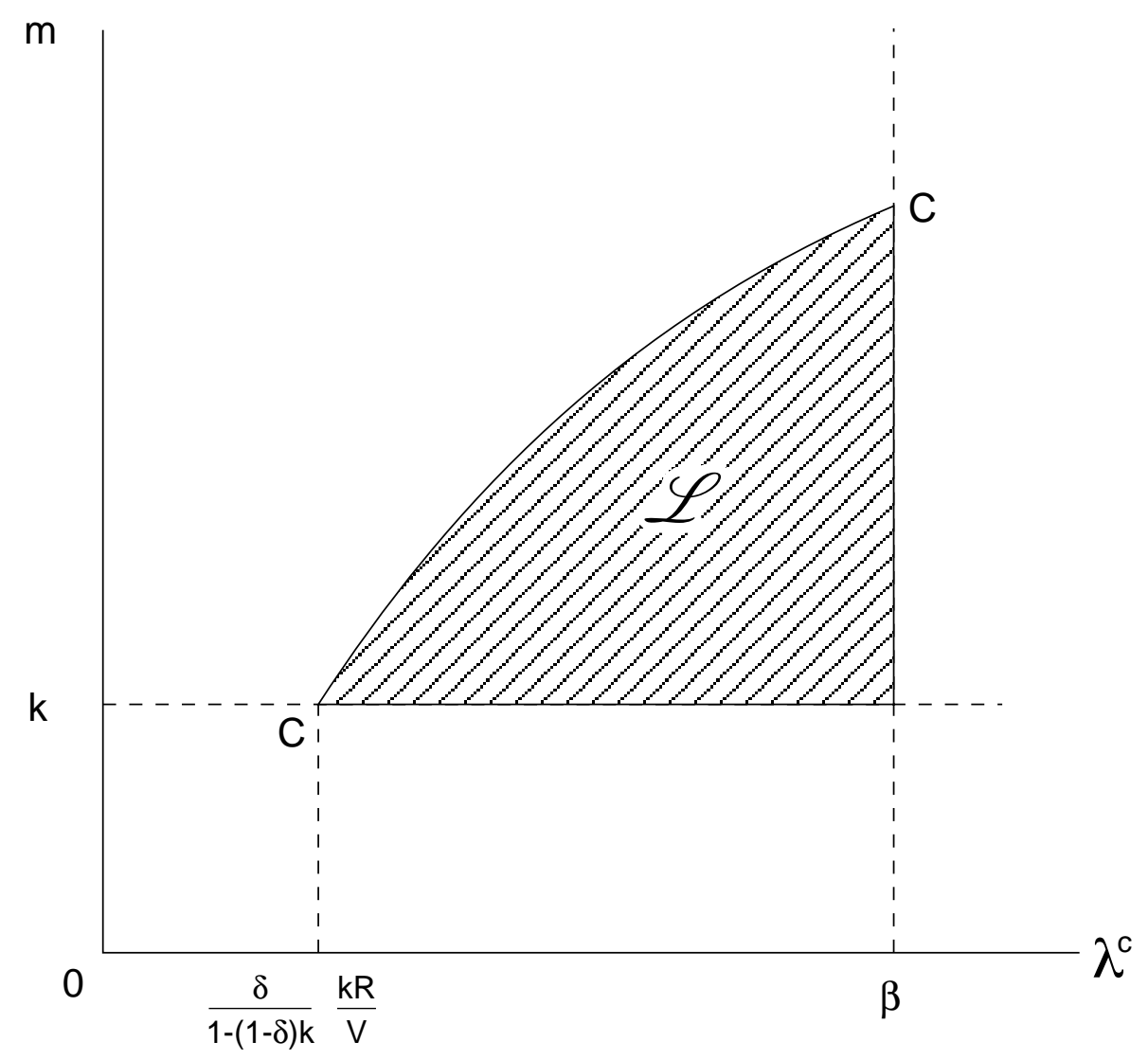

Figure 4. I is the set of pairs $\left(\lambda^{c}, \mathrm{~m}\right)$ such that the no undercutting condition (4.1) is satisfied. $\bar{m}$ is the number of relationship banks, and $\lambda^{c}$ is the fee charged by these banks in an equilibrium with relationships. $\lambda^{c}$ cannot exceed $\beta$ because firms would switch to fringe banks charging $\lambda^{\mathrm{f}}=0$. Locus $\mathrm{CC}$ traces the maximum number of relationship banks, $\overline{\mathrm{m}}$, for any given admissible fee $\lambda^{\mathrm{c}}$; or, conversely, the lower bound on the fee, $\underline{\lambda}^{\mathrm{c}}$, for any admissible number of relationship banks. 


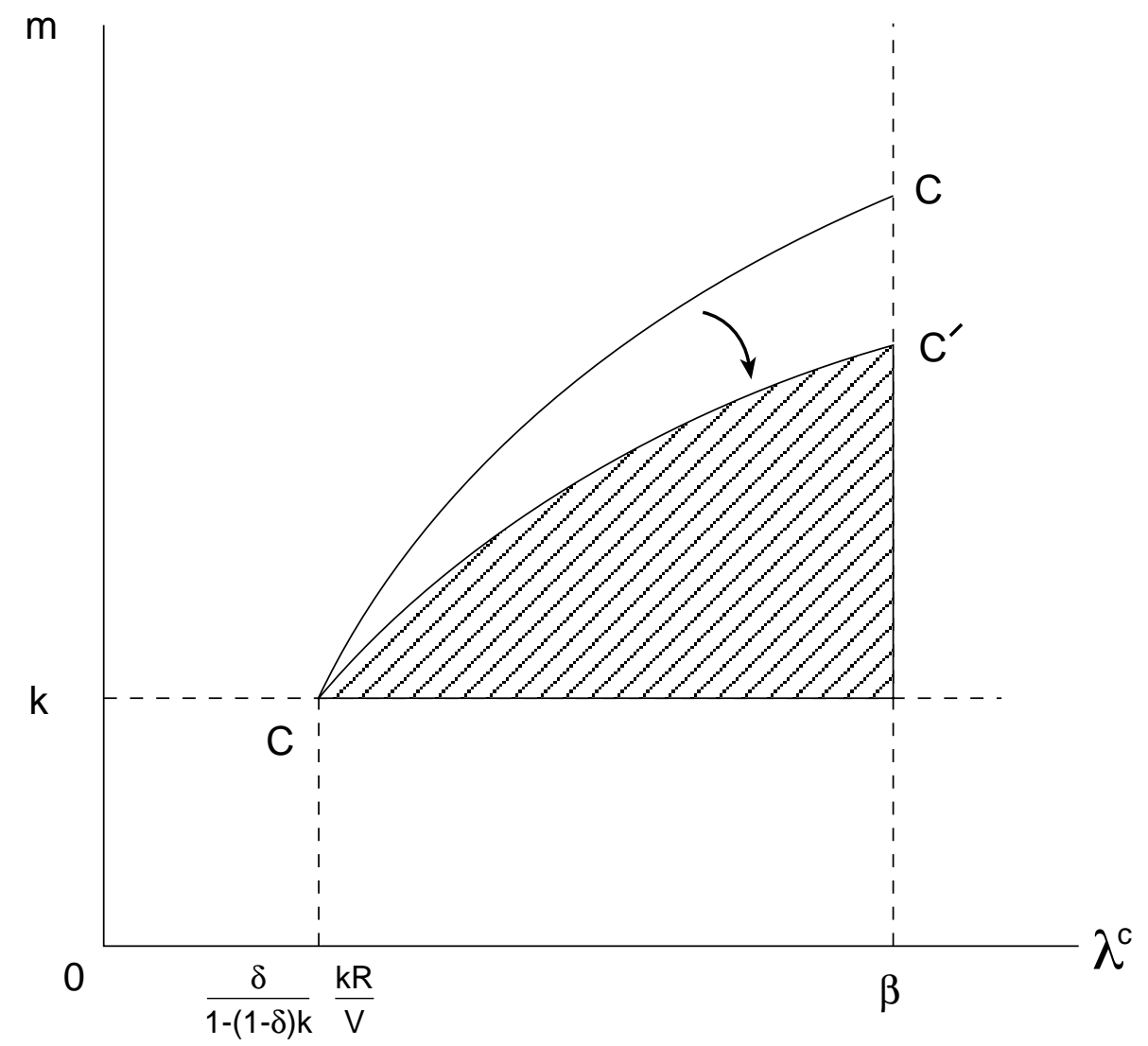

Figure 5. The effect on the no-undercutting locus $\mathrm{CC}$ of a smaller switching cost from a core bank to a non-core relationship bank.

Locus $\mathrm{CC}^{\prime}$ traces the effect of a smaller switching cost on the maximum number of relationship banks, $\bar{m}$, for any given admissible fee $\lambda^{c}$. The shaded region indicates the set of pairs $\left(\lambda^{\mathrm{c}}, \mathrm{m}\right)$ such that the noundercutting condition (4.1) is satisfied after a firm's cost to switch from a core to a non-core bank falls. 


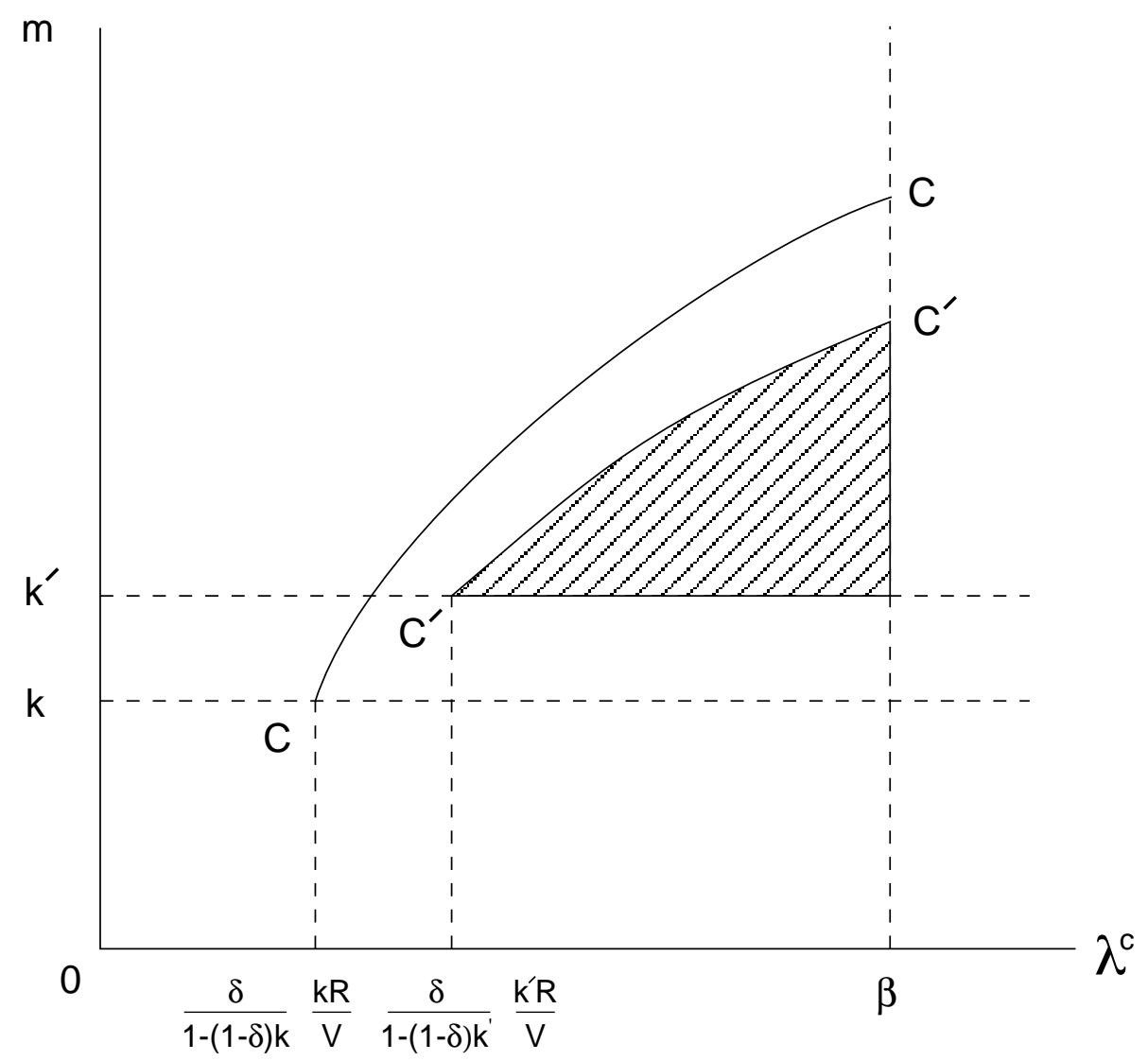

Figure 6. The effect of an increase in the number of relationships on the set of pairs $\left(\lambda^{\mathrm{c}}, \mathrm{m}\right)$ such that the no-undercutting condition $(4.1)$ is satisfied. The shaded region indicates the set of pairs $\left(\lambda^{\mathrm{c}}, \mathrm{m}\right)$ such that the no-undercutting condition (4.1) is satisfied after firms increase the size of the core group of relationship banks. 


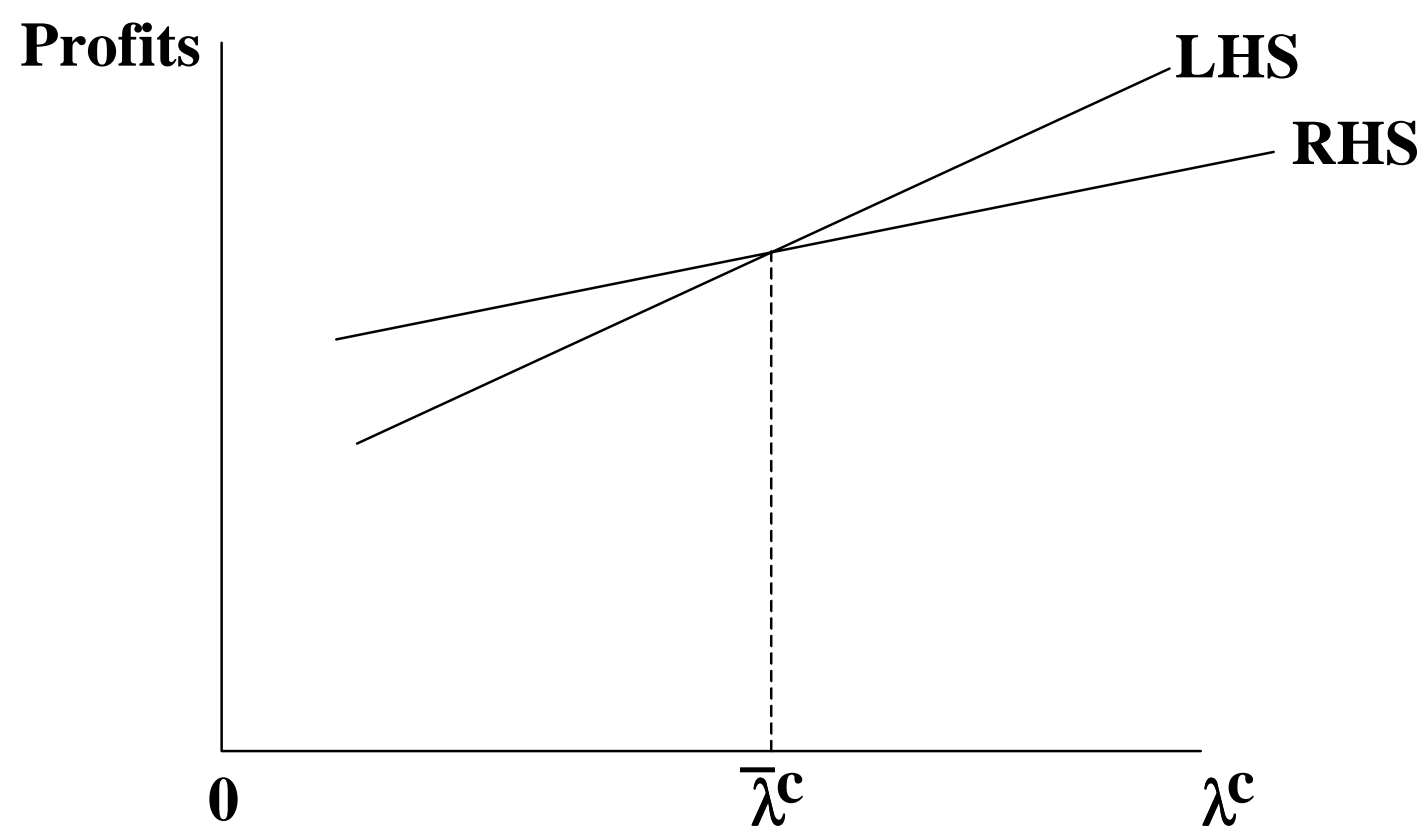

Figure 7. Non-price competition and the upper bound on fees. Locus LHS plots a relationship bank's long-run profits from continued cooperation as a function of the fee $\lambda^{c}$. Locus RHS plots a relationship bank's one-time profits when unilaterally undercutting after another relationship bank has unilaterally escalated sales efforts. The intersection of LHS and RHS is the upper bound on the fee that can be charged in any cooperative equilibrium. 